\title{
Thermal Comfort in Places of Worship within a Mediterranean Climate
}

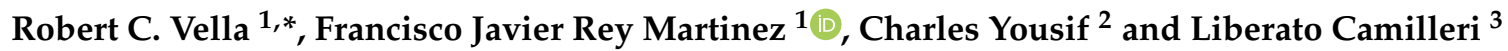 \\ 1 Departamento Ingeniería Energética y Fluidomecánica, Escuela de Ingenierías Industriales, \\ Universidad de Valladolid, 47011 Valladolid, Spain; rey@eii.uva.es \\ 2 Institute for Sustainable Energy, University of Malta, MXK 1531 Marsaxlokk, Malta; \\ charles.yousif@um.edu.mt \\ 3 Department of Statistics and Operations Research, Faculty of Science, University of Malta, \\ MSD 2080 Msida, Malta; liberato.camilleri@um.edu.mt \\ * Correspondence: peritrobertvella@gmail.com; Tel.: +356-9980-4481
}

Citation: Vella, R.C.; Martinez, F.J.R.; Yousif, C.; Camilleri, L. Thermal Comfort in Places of Worship within a Mediterranean Climate. Sustainability 2021, 13, 7233. https:// doi.org/10.3390/su13137233

Academic Editor: Adam Smoliński

Received: 1 June 2021

Accepted: 24 June 2021

Published: 28 June 2021

Publisher's Note: MDPI stays neutral with regard to jurisdictional claims in published maps and institutional affiliations.

Copyright: (c) 2021 by the authors. Licensee MDPI, Basel, Switzerland. This article is an open access article distributed under the terms and conditions of the Creative Commons Attribution (CC BY) license (https:// creativecommons.org/licenses/by/ $4.0 /)$.

\begin{abstract}
This paper investigates the relationship between the actual thermal comfort levels measured according to EN 16798-1 standard and the expected thermal comfort of attendees in five parish churches throughout 2018. This is carried out through statistical analysis of qualitative research based on questionnaire responses from church goers and quantitative research based on indoor measured data. This investigation includes the gathering of scientific data relating to temperature and relative humidity together with statistical data through thermal sensation surveys (TSSs). Thus, this study provides first-hand information about occupants' diversities of thermal sensations and dynamic behaviour adaptations to the intricate environment within churches. Results determine that a significant correlation exists between the actual thermal comfort levels measured according to EN 16798-1 standard and the expected thermal comfort perceived by the church attendees in most of the parish churches under review. Analysis of the sources of discomfort and suggestions made by the occupants revealed that passive design measures contribute towards improved indoor thermal conditions, reduced energy demand and lower carbon emissions. This information provides assurance for optimised decision-making methods, used to generate accurate solutions for policymakers, architects and engineers, with an understanding of practical applications of passive measures for places of worship. Moreover, the paper provides insight on indoor comfort levels in places of worship within a Mediterranean context, which is insufficiently addressed by scholars at a global level.
\end{abstract}

Keywords: thermal comfort; churches; indoor temperature; thermal sensation surveys; relative humidity

\section{Introduction}

The physical location of the parish churches in the archipelago of Malta, within the heart of Maltese villages or towns, is of paramount importance in presenting them as central icons within the everyday life of the community [1]. It is a truism to state that Malta has changed over the past 20 years, and so did comfort expectations [2]. The demand to create comfortable indoor thermal environments is no longer considered a luxury, and this has brought unforeseen challenges in places of worship, particularly because these buildings were not designed to be mechanically heated or cooled. Hence, the urge to create the expected 'adequate' indoor thermal environments without altering the general indoor microclimate has contributed to the growth of research on the subject.

The term 'thermal comfort' remains subjective and may be considered as a mindset that depends on the combination of the individual's social and cultural expectations and the physical thermal environment. Those who are accustomed to a higher level of thermal conditions are more likely to acclimatise to thermal homogeneity, while those who experience different thermal conditions throughout the day can better adapt to variations [3]. It 
is a proven fact that through self-adaptation, the human physiological indicators generate adaptive measures to address the changes in indoor operative temperatures [4]. Such adaptation often results in attaining thermal comfort and prevents the use of energy for heating and cooling [5].

To this effect, occupants' thermal comfort feedback is imperative to energy efficiency analysis. Studies show that by the implementation of passive design measures, it is likely to broaden the non-heating and cooling periods [6-8], rendering a more comfortable environment. It is pertinent to point out that Directive (EU) 2018/844 of the European Parliament and of the Council of 30 May 2018 (amending Directive 2010/31/EU on the energy performance of buildings and Directive 2012/27/EU on energy efficiency) encourage research on historical buildings, including churches, to improve their energy performance ratings [9].

This research supports researchers in promoting the study of passive and low-energy architecture [10]. However, thermal comfort within buildings and the urban heat island effect remain of major concern, and adopting low-energy passive design strategies worldwide is not an option but a must in today's global climate change and emerging infectious diseases [11].

Research in indoor thermal comfort of free-running historical places of worship is often limited to comparison of measured data to the predicted adaptive thermal comfort models.

The aim of this paper is to go a step further and investigate the relationship between the actual thermal comfort levels measured according to EN 16798-1 standard and the expected thermal comfort as experienced by the attendees in these five parish churches throughout 2018. The study is extensively based on solid statistical analysis procedures of 600 questionnaire responses that were collected from church goers, both in summer and in winter seasons, as well as quantitative research based on indoor measured data. The uniqueness of this paper is portrayed in the combination of statistical methods that analyses the outcomes of real user experiences in naturally ventilated places of worship with thermal comfort studies based on adaptive thermal comfort models, as well as the comparison between the impact of building construction practices throughout different eras on the level of thermal comfort. This is combined with the result of identifying potential solutions to thermal comfort, by data analysis and consultation with the target population, in a cluster of buildings that have so far received insufficient attention from scholars and regulatory institutions.

\subsection{Church Buildings under Study}

Analysis of the physical and environmental factors was conducted for a number of churches, termed 'reference buildings' (RBs). These RBs characterise the different types of churches in Malta and portray 'real examples' with typical, physical and occupational characteristics as proposed by Ballarini et al. [12]. Out of the 359 churches on the Maltese islands, five RBs were specifically chosen. Selection was based on era, construction methodology and materials, form and occupational characteristics. The eras covered are 17th to mid-18th century Baroque period (Balzan, Sliema and Msida parish churches), mid-20th century neo-Romanesque style architecture (Santa Venera parish church) and late 20th century (post Vatican Council II style) contemporary architecture (Fgura parish church) (refer to Figure 1).

\subsection{Analysed Factors}

The Maltese islands lie within the subtropical zone and therefore experience a typical Mediterranean climate with high levels of humidity [13]. Due to the limited area of the Maltese archipelago $\left(316 \mathrm{~km}^{2}\right)$ and the homogeneity of the land, only one climatic zone is defined [14]. These high levels of relative humidity hinder evaporative cooling, leading to an uncomfortable sensation typical of hot and humid climates, as well as higher perceived coldness in winter $[15,16]$. The impact of relative humidity and ambient air temperature are considered as determining environmental factors in this study. 


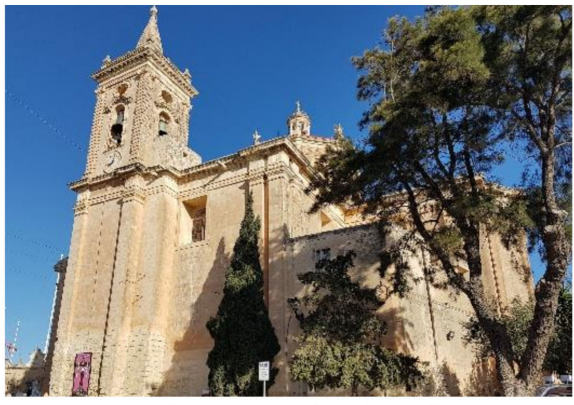

Balzan Parish Church

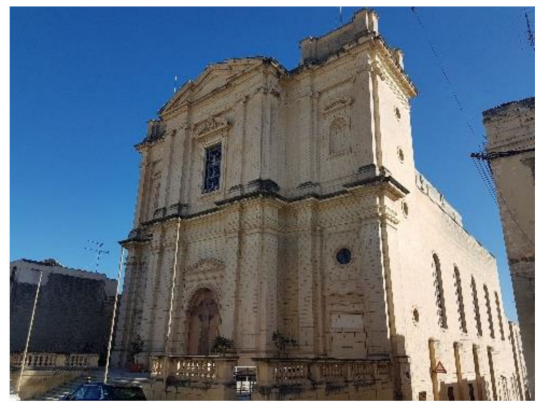

Santa Venera Parish Church

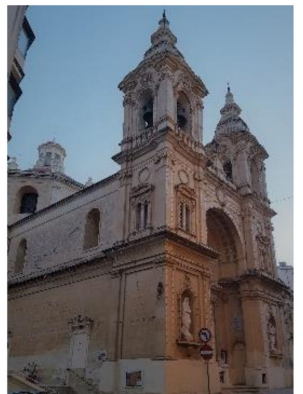

Sliema Parish Church

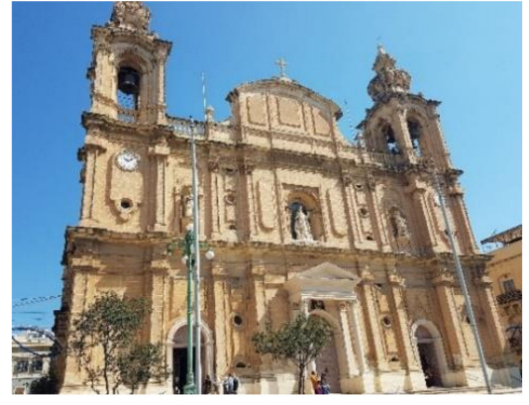

Msida Parish Church

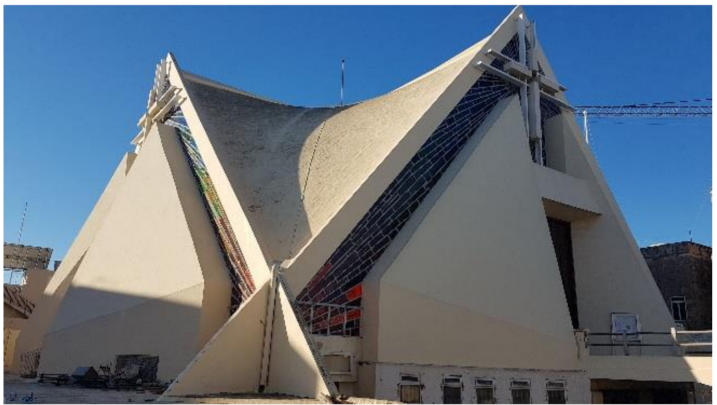

Fgura Parish Church

Figure 1. RBs: Balzan Parish Church (1669-1695); Stella Maris Parish Church, Sliema (1853-1877); Msida Parish Church (1867-1889); Santa Venera Parish Church (1954, still with incomplete bell towers); and Fgura Parish Church (1988). Dates shown indicate the period of construction.

In addition to the weather variables, the different construction methodologies of the 'reference buildings' (RBs) were analysed. Comparison is made between the modern building slender reinforced concrete structures and the thick walls made of globigerina limestone found in traditional churches. The thickness of the wall affects the thermal inertia, with thicker walls flattening internal temperature fluctuations and improving thermal comfort [17]. The sectional elevations displayed in Figure 2 show the very thick globigerina limestone walls of the Msida Parish Church (ranging from $1000 \mathrm{~mm}$ to over $1900 \mathrm{~mm}$ ) in comparison to the evolved construction methods of the contemporary reinforced concrete adopted in the Fgura Parish Church $(150 \mathrm{~mm})$, whereby the stability of the building results from its shape rather than its sheer mass.
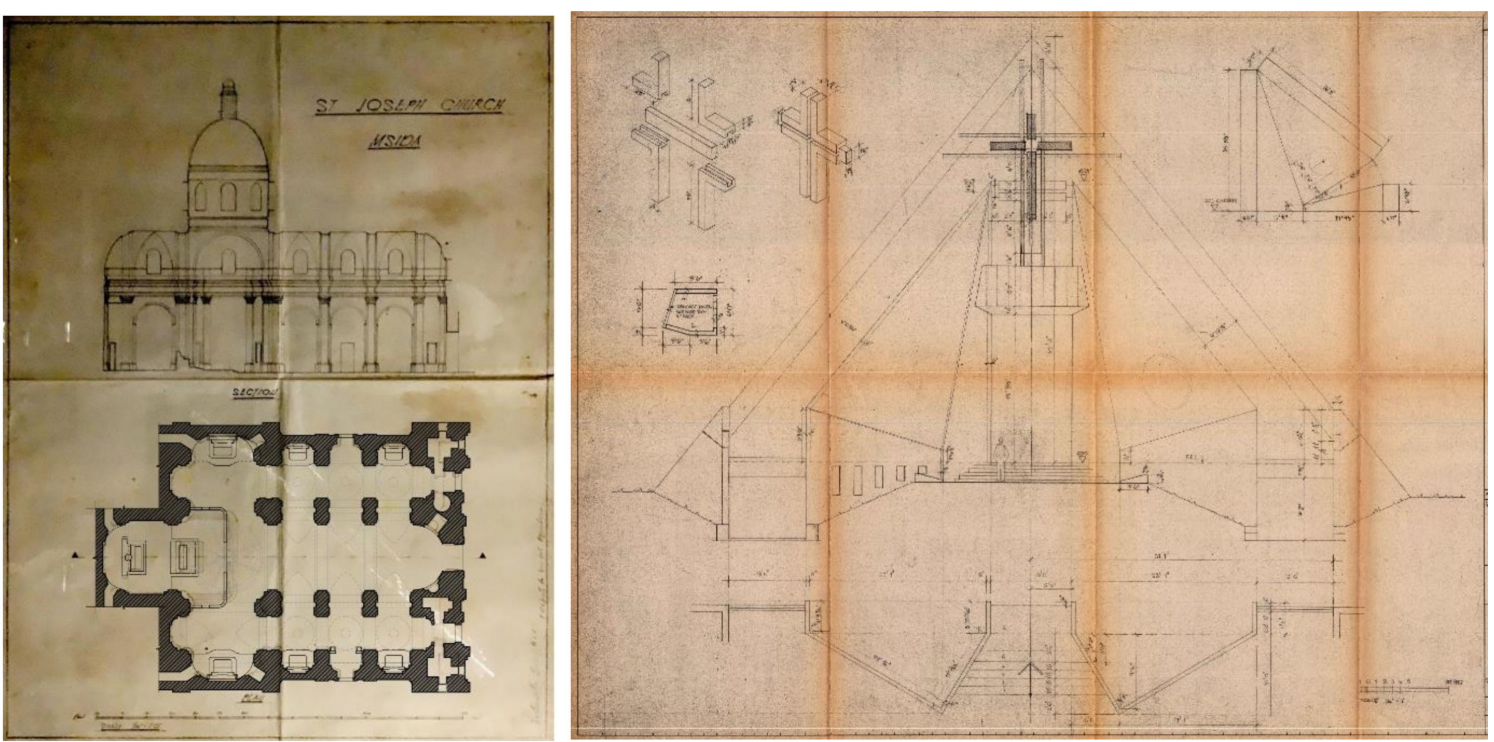

Figure 2. Sectional elevations of Msida Parish Church and Fgura Parish Church. Curtesy of the Archdiocese of Malta. 
Other parameters such as orientation (refer to Figure 3), window-to-wall ratio, solar heat gains through non-operable windows, low insulation levels of the building envelope and lack of air movement all proved to have a direct effect on the indoor comfort of the building and the ultimate ambient temperature and indoor environment [18-20]. On the other hand, the qualitative study of the church attendees took into consideration individual attributes such as age [21] and gender [22,23].
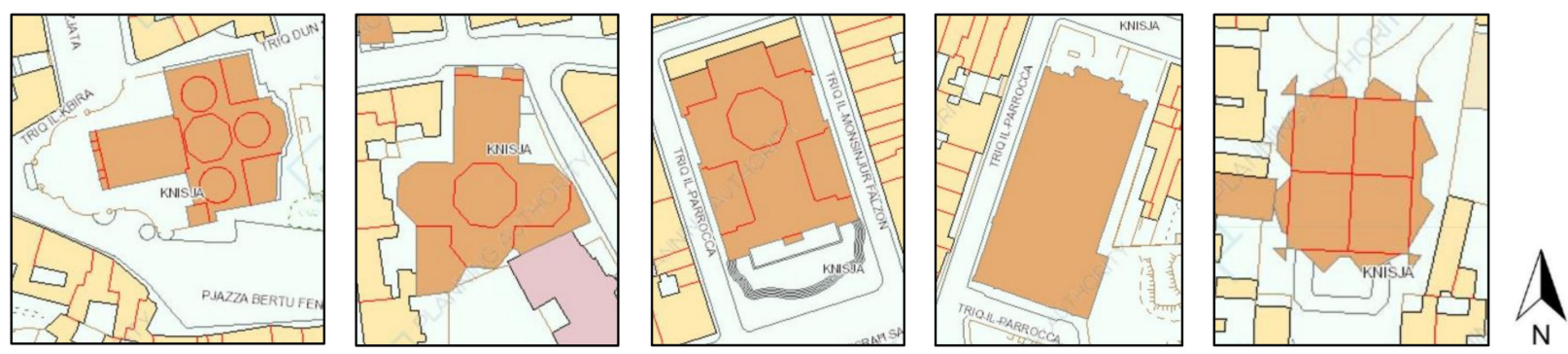

Figure 3. Orientation of the RBs (not to scale) left to right: Balzan Parish Church; Stella Maris Parish Church, Sliema; Msida Parish Church; Santa Venera Parish Church; and Fgura Parish Church. (For all RBs, the north direction is vertically upwards.)

It is pertinent to note that since Malta enjoys high levels of solar irradiation [24], the internal ambience of buildings gets hotter in summer because the rate of heat transfer between external solar-exposed surfaces and internal surfaces increases and also due to the fact that churches many times leave their doors open, allowing warmer air to infiltrate into the indoor zones. Furthermore, since the Maltese Islands lie within the subtropical zone, buildings are exposed for a longer period of time to solar radiation especially during the summer months. According to the Meteorological Office of the Malta International Airport in 2018, the brightest day in July had a total of 14 hours' worth of sunlight with a recorded temperature of $35.7^{\circ} \mathrm{C}$ [25].

\section{Method}

The methodology adopted to conduct the investigation on the actual thermal comfort within the selected RBs and the expected thermal comfort of the occupants within the same RBs, together with onsite measurements and TSSs, is explained below.

\subsection{Adaptive Comfort Model}

The adaptive model adopted examines the relationship between church goers and the respective places of worship. This is based on the concept that individuals respond to uncomfortable changes by adapting to restore comfort. Such adaptation incorporates a combination of physiological, psychological and behavioural characteristics [26-28]. This model considers the indoor temperature as being strongly dependent on the outdoor temperature, providing a wider range of temperatures more acceptable to the users [29]. To this effect, the EN 16798-1 adaptive comfort model was adopted [30,31]. It must be noted that the difference between the operative temperature (used in standard EN 16798-1) and the apparent temperature, directly measured from the data loggers, is insignificant [32].

It is pertinent to point out that Balzan and Sliema parish churches were equipped with air-conditioning systems to be used intermittently for cooling during weekend and feast day religious services during warm periods. However, they were not being utilised when the TSSs were being conducted. Thus, churches were considered as free-running (naturally ventilated), and the adaptive comfort model was adopted as opposed to the heat balance model (PMV / PPD model). Furthermore, since churches are occupied for a relatively short time, category III comfort level was chosen to reflect an adequate level of expectation [33].

\subsection{Onsite Measurements}

The RBs were monitored by means of data loggers Onset HOBO MX1101, for the full year of 2018. Each RB had four data loggers, one placed at the back of the main 
nave, another at the centre of the main nave, the third placed at the altar and one external station in indirect sunlight. Air temperature $\left({ }^{\circ} \mathrm{C}\right)$ and the percentage relative humidity (\%) for the interior and exterior environments were continuously measured at $5 \mathrm{~min}$ instantaneous intervals [34]. The indoor carbon dioxide levels were recorded for a sample week using an MX1102 $\mathrm{HOBO}$ MX $\mathrm{CO}_{2}$ Logger [35]. The indoor humidity levels of walls expressed as percentages were recorded at $0.5 \mathrm{~m}$ height of walls from finished floor level (FFL) using the Powerfix HG03064C Moisture Meter. An average of six humidity level readings were recorded along the main aisle for each $\mathrm{RB}$. Moreover, sample data for indoor radiant temperatures were recorded over a one-week period using the MRC wet bulb globe temperature logger Model WBGT-2010SD. Radiant temperature is defined as a measure of the average temperature of all surfaces, which can be different from air temperature under specific conditions.

The 5 min interval indoor air temperature readings recorded in each parish church throughout the year 2018 were transposed to hourly values. These data were then analysed and plotted as a 5-day moving average in the form of line graphs in relation to comfort limits determined by EN 16798-1.

It is pertinent to point out that prior to transposing from hourly values to a 5-day moving average, it was made sure that there was no substantial difference in the recorded indoor air temperature between occupied and unoccupied hours, more so during the presence of large congregations where only limited sporadic minor fluctuations were noted.

\subsection{Mathematical Statistics}

To establish the relationship between the actual thermal comfort levels measured according to EN 16798-1 standard and that expected by the parishioners, several statistical tests were carried out. Each test specifies two hypotheses, where the null hypothesis specifies that the two categorical variables are independent implying that there is no association between them. The alternative hypothesis specifies the converse (i.e., that the two categorical variables are not independent). Moreover, a 0.05 level of significance was adopted for each test [36].

In order to conduct the investigation on the expected thermal comfort of the occupants within the selected churches, a quantitative, correlational design research was employed [37]. This research is used to examine any correlation between two or more variables through statistical analysis.

\subsection{Recruitment Method and Study Population}

Whilst the microclimate was being monitored, surveys with sample parishioners were carried out in each RB for both summer (represented by May to September) and winter (represented by November to March) during the peak period of extreme weather. The data were collected through cluster sampling method in which there is an equal probability of respondents being chosen in order to achieve an unbiased representation of the total population [38]. Sixty participants from each RB, totalling 300 participants, were surveyed in summer and another 300 participants were surveyed in winter. Hence, the total study population was that of 600 participants (291 males and 309 females with a mean age of 49.31 years and a standard deviation of 16.778 years), which guarantees a maximum margin of error of $4 \%$ assuming a $95 \%$ confidence interval.

\subsection{Survey Design}

The survey addressed one's current thermal state (CTS) inside the church through a 7-point Likert scale [39], where 1 represents the 'hot' extreme and 7 represents the 'very cold' extreme. In accordance with Hawkes' conclusions [40], the 'neutral' point represented as 0 on the Likert scale is interpreted as the point at which the participant is thermally comfortable. On the other hand, S. Shahzad et al. (2018) concluded that measures other than CTS may be needed to fully analyse the thermal comfort of users, such as thermal preference [41]. However, it must be considered that the latter study investigated the 
application of the neutral thermal sensation within office buildings with an average of eight working hours daily, which is a significant amount of time when compared to about $45 \mathrm{~min}$ spent in churches. Thus, the CTS of the parishioners is a good indication to analyse the thermal comfort within the RB. Other questions in the TSS included frequency and time of attendance, whether participants ever attended a different church due to uncomfortable temperatures, whether they ever missed Sunday prayer service due to temperature extremities and identification of sources of discomfort and suggestions to reduce them [42]. Relevant personal data of every participant were also recorded, including age, gender and clothing.

\section{Results and Discussion}

Analysis of results displayed in this section is divided into two parts. The first part (refer to Section 3.1) investigates the actual thermal comfort of the RB in accordance with EN16798-1 standard, whilst the second part (refer to Section 3.2) investigates the expected thermal comfort perceived by the occupants within the RB.

The scope of the results displayed in Section 3.1, including their respective analysis, is to determine whether the RBs are termed as thermally comfortable. These results are then compared with the expected thermal comfort perceived by the occupants deduced in Section 3.2 to determine any correlation between the actual thermal comfort and the expected thermal comfort within the RB.

\subsection{Actual Thermal Comfort (EN 16798-1)}

The Baroque comfort analysis graphs (Balzan, Sliema and Msida) displayed in Figure 4 illustrate similar trends of line data, having the indoor air temperature intersecting the lower limit established from the EN16798-1 standard, approximately at the beginning of May and at the end of November. More importantly, during these months (May to November), the indoor air temperature is persistently situated below the upper limit (EN16798-1). Thus, this result signifies that during these months, these parish churches are termed as thermally comfortable.

Similar time frame intercepts between the recorded indoor air temperature and the established lower limit (EN16798-1) are displayed in the more contemporary parish churches (St Venera and Fgura). However, it is pertinent to point out that during these months (May to November) the indoor air temperature is significantly closer to the upper limit (EN16798-1), where that of the St Venera parish church exceeds this limit for a short period during the month of August.

Further analysis on the relationship between the recorded indoor and outdoor air temperatures reveals that these do not fluctuate in tandem for the Baroque parish churches, as the indoor air temperature is steadier when compared to that of the outdoor temperature. This is not the case in the contemporary parish churches as, overall, both the recorded indoor and the outdoor air temperatures fluctuate in tandem. This result is attributed to the different methodology of construction in the building envelope between the Baroque and contemporary parish churches, where the U-values are significantly lower amongst those of the Baroque.

It can also be pointed out that the margin difference in degrees Celsius $\left({ }^{\circ} \mathrm{C}\right)$ between the recorded indoor and outdoor air temperatures of the contemporary parish churches is more significant in the St Venera parish church than that for the Fgura parish church. This is also attributed to the building envelope of both churches, where although they are termed as both contemporary, the St Venera parish church is a mid-20th century neo-Romanesque style architecture and the Fgura parish church is a late 20th century (post Vatican Council II style) contemporary architecture. This difference in architecture styles is seen through the distinct methodology of construction and building materials. The St Venera parish church is constructed of double-leaf masonry load-bearing walls (lower globigerina limestone) supporting reinforced pre-cast planks. The walls are formed of $0.23 \mathrm{~m}\left(9^{\prime \prime}\right)$ thick blocks per leaf, with a concrete infill in between, resulting in an overall U-value of $1.8 \mathrm{~W} / \mathrm{m}^{2} \mathrm{~K}$. On 
the other hand, the Fgura Parish church is constructed using reinforced concrete structure built in the form of identical triangular segments and large stained-glass panels with an overall structural U-value of $2.52 \mathrm{~W} / \mathrm{m}^{2} \mathrm{~K}$.
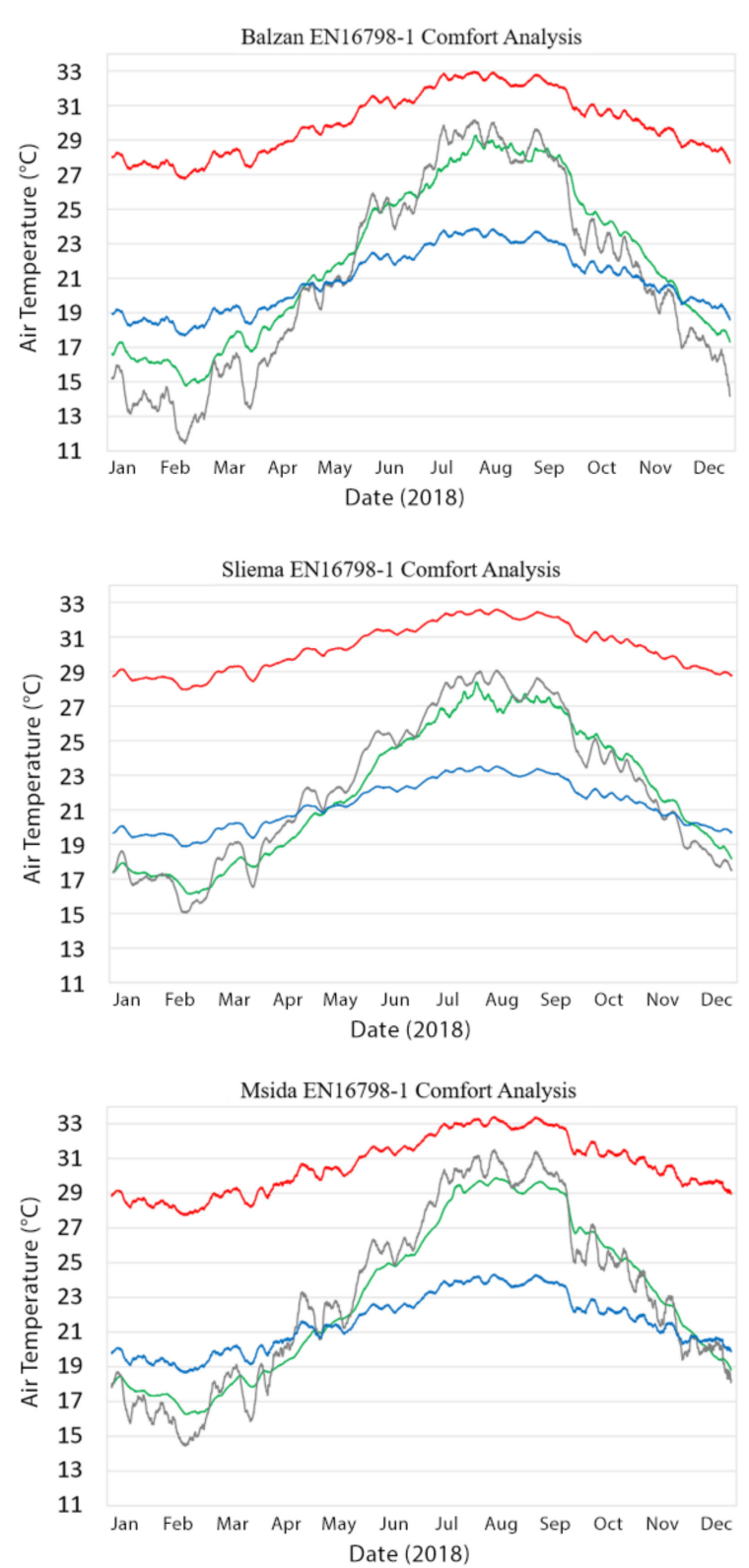
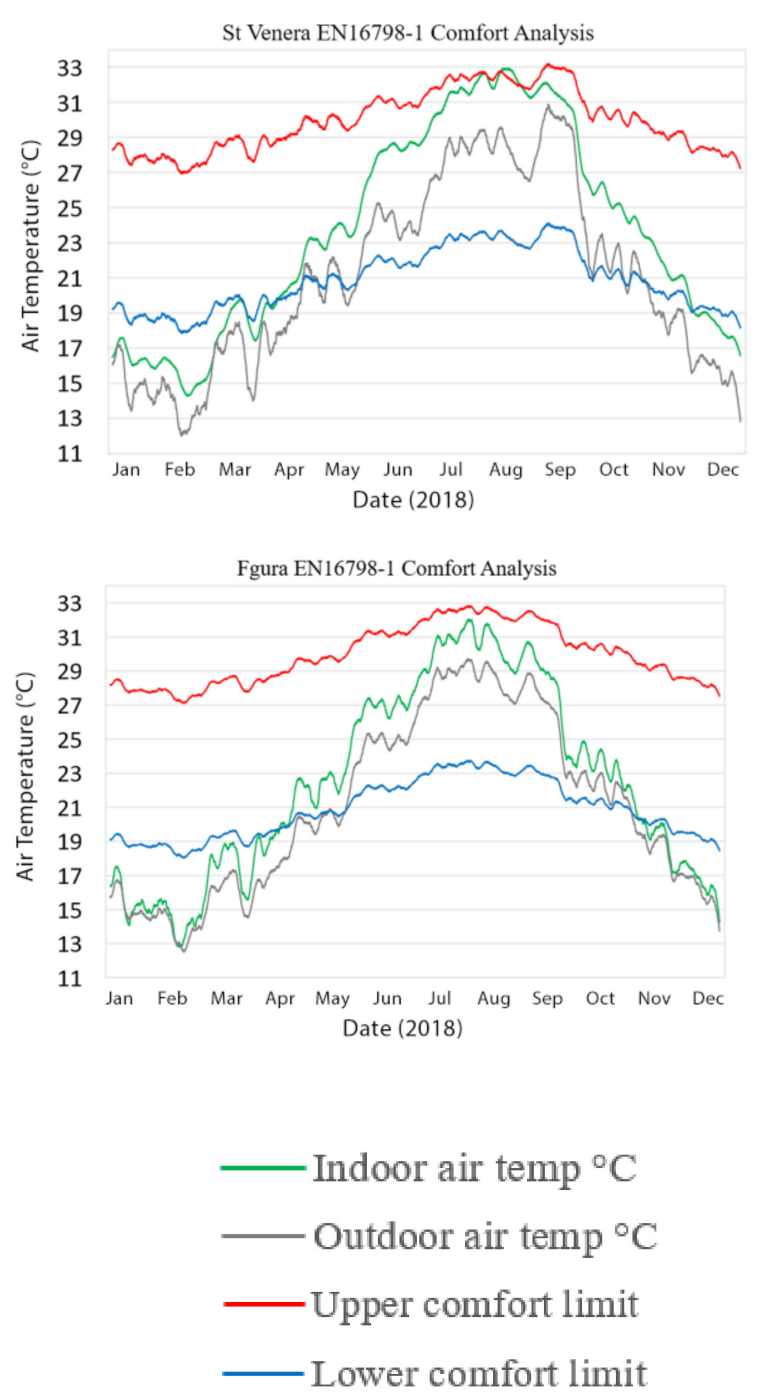

Figure 4. EN16798-1 category 3 comfort analysis.

The thermal comfort within the RB is mainly found by analysing the indoor air temperature with the relative comfort limits as calculated by the EN16798-1 standard method. Although thermal comfort does not depend solely on temperature, it can be deduced from the data collected in this study that air temperature is sufficient to indicate the level of thermal comfort, given that internal wind speed is low and the radiant temperature is very close to that of air temperature, as demonstrated in the results section.

This was further confirmed through a monitoring campaign in the five selected churches, results of which show that the indoor radiant and ambient temperatures were remarkably close in value, as shown in Figure 5. 

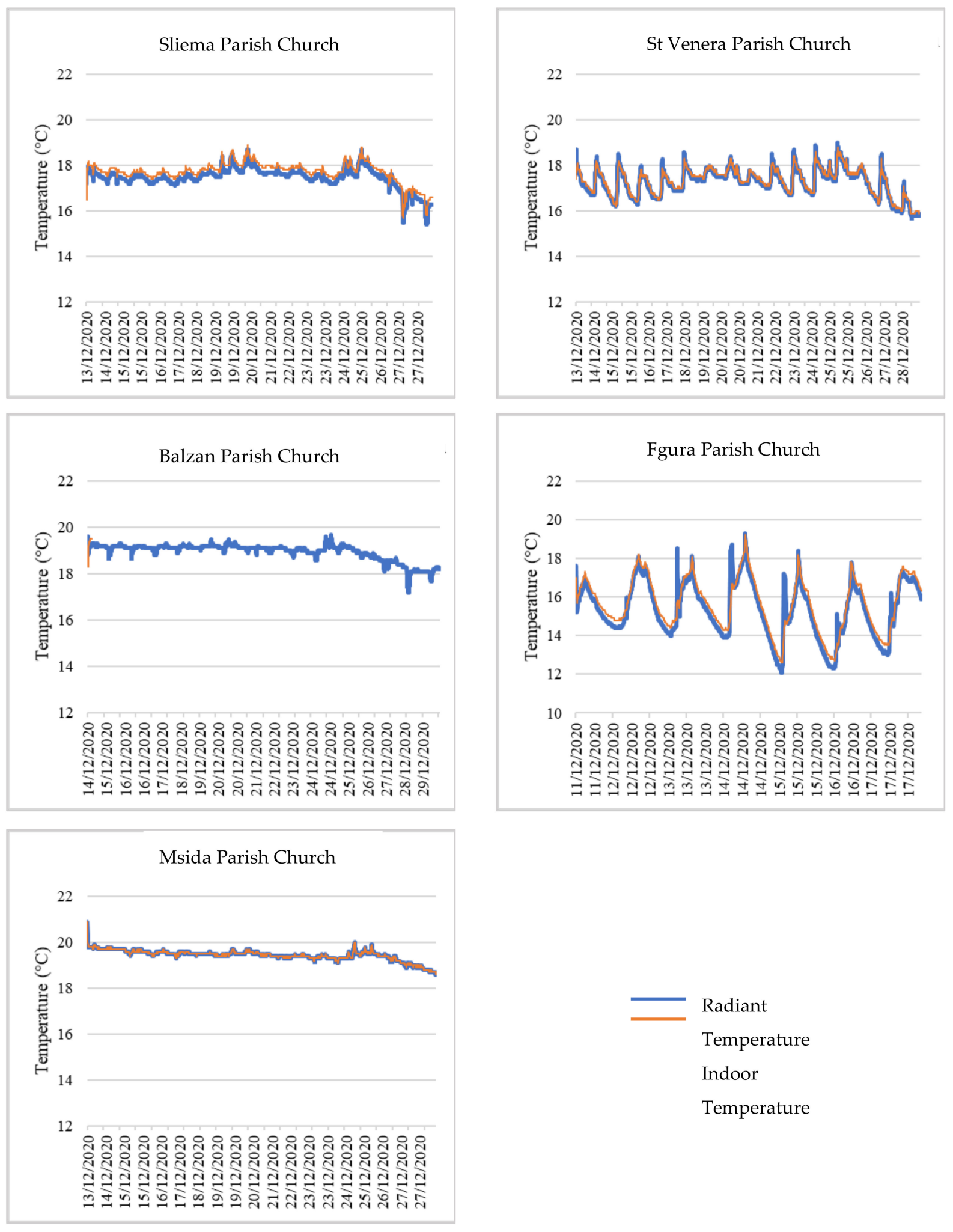

Temperature

Figure 5. Indoor radiant and ambient temperatures.

\subsection{Expected Thermal Comfort}

This section focuses on statistical data analyses using the IBM Statistical Package for the Social Sciences (SPSS) program version 26 [43] to determine the expected thermal comfort perceived by parishioners and its response to the actual indoor thermal environment by considering the factors affecting thermal perception. Most of the variables being studied 
are categorical, and the only way to investigate the association between these variables is to carry out the chi-squared test. One of these variables is the parish church (Balzan, Sliema, Msida, St Venera, Fgura), whilst the other variable describes the respondents' views regarding suggestions, sources of discomfort and comfort level [44]. There are two tests that can be used to investigate the association between two categorical variables, and these include the Pearson chi-squared test and the likelihood ratio test. However, when the sample size is large, the $p$-values of these two tests converge. Thus, in this paper, the Pearson chi-squared test was used as the likelihood ratio test yielded almost an identical $p$-value to that of the Pearson chi-squared test [45].

On the contrary, some of the variables such as age, humidity and temperature are continuous (have a metric scale), and for these variables, the one-way ANOVA test was chosen to analyse the different parameters between the parish churches after checking the normality assumption. The one-way ANOVA test was used to compare mean temperature and mean humidity between the five parish churches, and this was carried out for each month. Moreover, this test was also used to compare mean ages of parishioners between the five parish churches to confirm that it is not a confounding factor.

The following SPSS results are displayed in a mixture of both graphical and tabular format to avoid redundancy of information. In addition, in all the analyses, the chi-squared test yielded $p$-values that were less than the 0.05 level of significance, indicating that the two categorical variables are not independent. In other words, there was a significant association between the two variables, thus the alternative hypothesis is satisfied. It must be pointed out that during the summer period on the day when the TSSs were being conducted, all the RBs were termed as being thermally comfortable in accordance with EN16798-1 and thermally uncomfortable during the winter period.

\subsection{Perceived Comfort Level}

During the summer period (refer to Figure 6), the Baroque parish churches of Balzan $(81.7 \%)$, Sliema (50\%) and Msida (43.3\%) resulted in having the most relatively 'neutral' environment. The contemporary parish churches resulted in having a lower percentage of participants selecting a 'neutral' environment with $16.7 \%$ of votes for St Venera parish church and $6.7 \%$ of votes for Fgura parish church. On the other hand, the contemporary parish churches resulted in having a significantly higher percentage of occupants voting for 'very hot' with Fgura having a total of 73.3\% and St Venera parish church having 38.3\%, with lower percentages registered in the Baroque parish churches of Msida (25\%), Sliema $(26.7 \%)$ and Balzan (0\%). This result signifies that most occupants were satisfied in terms of comfort within the Baroque parish churches, while in the contemporary parish churches, the majority were dissatisfied.

With regards to winter, Figure 6 also shows that the Baroque parish churches of Sliema and Msida, apart from Balzan, have a generally higher degree of 'neutral' votes (56.7\% and $43.3 \%$, respectively) when compared to the contemporary parish churches (St Venera $3.3 \%$ and Fgura $28.3 \%$ ). In fact, the contemporary parish churches had a higher degree of 'cold' votes (St Venera 63.3\% and Fgura 46.7\%) when compared to Msida and Sliema Baroque parish churches $(36.7 \%$ and $13.3 \%$, respectively). When comparing these results with those established in Section 3.1, it can be deduced that there is a correlation between the actual and expected thermal comfort within the Balzan, St Venera and Fgura parish churches. However, this does not apply to the Sliema and Msida parish churches as most of the votes are neutral. This is possibly attributed to other factors that influence indoor thermal comfort, investigated in further detail below.

$$
\begin{gathered}
X^{2}(12)=121.74, p<0.001 \text { (Summer) } \\
X^{2}(16)=160.55, p<0.001 \text { (Winter) }
\end{gathered}
$$

where the number in brackets is the degrees of freedom $(\mathrm{df}=($ Rows -1$) \times($ Columns -1$))$ and the value for $\mathrm{X}^{2}(\mathrm{df})$ is the chi-squared value. 


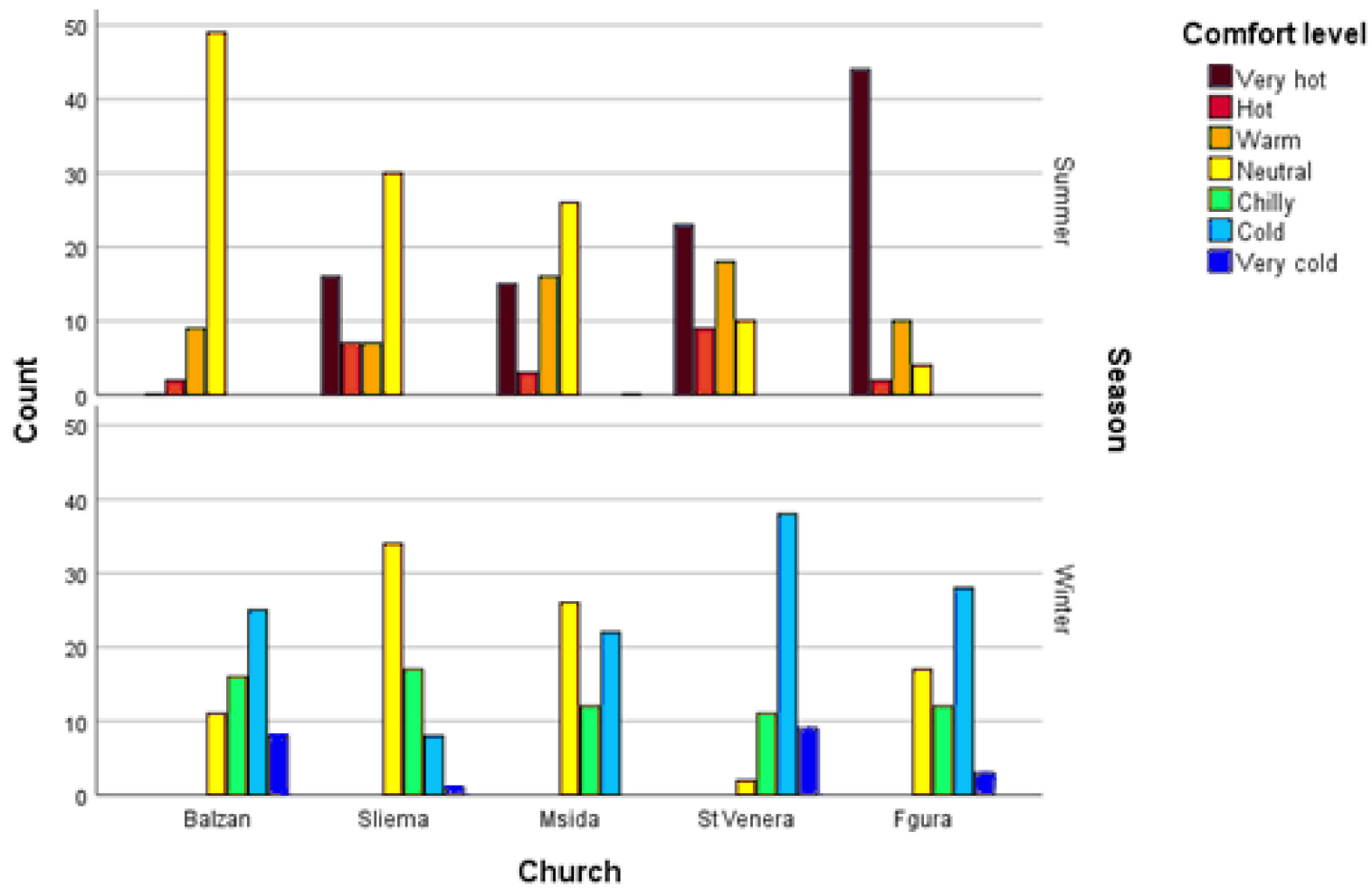

Figure 6. Bar graph representing different comfort levels in the different parish churches in summer and winter.

The reason behind the high percentage of 'neutral' voting amongst the Baroque parish churches is mainly attributed to their respective thermal transmittance. This relatively low $\mathrm{U}$-value, ranging from 0.49 to $0.54 \mathrm{~W} / \mathrm{m}^{2} \mathrm{~K}$, contributes to low thermal losses or gains through the building material thus maintaining a neutral environment. In addition to the above, these churches have a low percentage of glazed areas, and many of these windows are glazed with stained glass.

With regards to the contemporary parish churches, it can be noted that the U-values for St Venera parish church $\left(1.8 \mathrm{~W} / \mathrm{m}^{2} \mathrm{~K}\right)$ and Fgura parish church $\left(2.52 \mathrm{~W} / \mathrm{m}^{2} \mathrm{~K}\right)$ are significantly higher than those of the Baroque parish churches under review, thus contributing to a higher degree of heat transfer through the building fabric, resulting in an overall more uncomfortable environment. Moreover, the percentage of glazed apertures is higher, allowing a higher percentage of solar radiation to penetrate and overheat the indoor climate in summer. On the other hand, with $28.3 \%$ 'neutral' votes, the high percentage area of glazing in the Fgura parish church has helped it achieve a better indoor thermal comfort during the winter than that recorded in the Balzan parish church.

\subsubsection{Summer}

The results from the survey reveal a trend in the thermal comfort of the RB ranging from the most thermally comfortable to the least thermally comfortable as illustrated in Figure 7. The Balzan parish church ranked as the most thermally comfortable out of all the parish churches under review in summer.

Analysing in further detail the difference in the indoor environment between the Fgura and St Venera parish churches, it can be noted that the comfort levels voted by the parishioners vary amongst the two. In the case of St Venera, although 38.3\% selected 'very hot', 30\% selected 'warm' and 16.7\% 'neutral', thus resulting in having a more comfortable indoor environment when compared to that of Fgura parish church, where most of the occupants selected 'very hot' (73.3\%). 


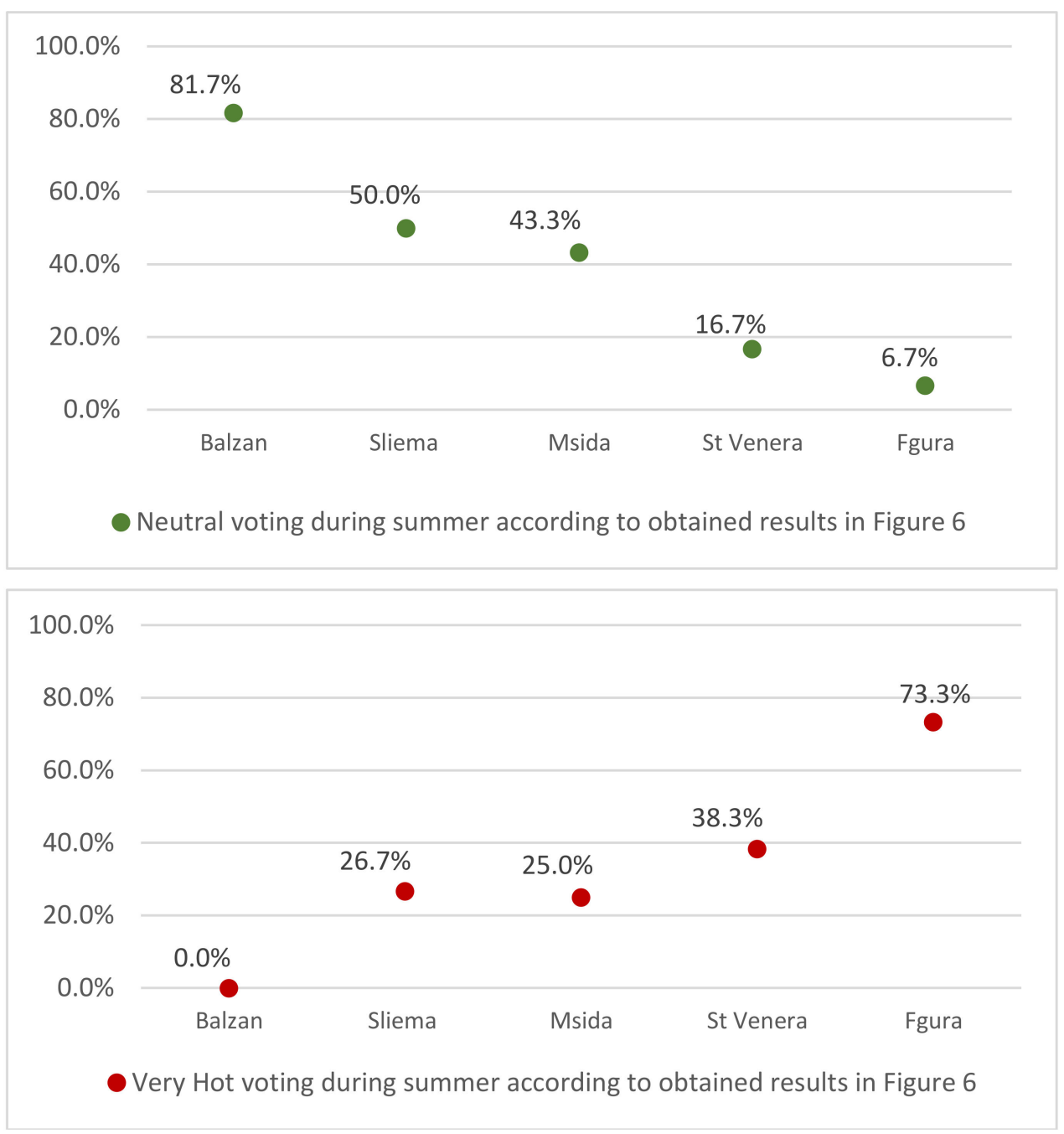

Figure 7. $X-Y$ Scatter graphs showing the comfort level in accordance with the results obtained in Figure 6 during summer.

In contrast, from the bottom graph of Figure 8, it can be observed that the monthly mean indoor temperature of the St Venera parish church is recorded as being higher than that of Fgura parish church by approximately 1.5 degrees Celsius for every month. Hence, one would assume that occupants should feel hotter in the St Venera parish church. However, the top graph of Figure 8 illustrates that the St Venera parish church maintains a relatively low monthly mean percentage of relative humidity throughout the summer when compared to a higher monthly mean humidity in the Fgura parish church. As the air temperature becomes warmer, the relative humidity decreases [46], resulting in a negative relationship as portrayed in Figure 7.

This elevated relative humidity in the Fgura parish church is highly likely to be the reason for most occupants voting 'very hot' $(73.3 \%)$, besides the elevated temperatures. This is because high relative humidity influences thermal perception as it hinders evaporation through the skin, resulting in a sweaty feeling. Furthermore, thermal perception may also be affected by the penetration of direct sunlight through the large area of oriented glazed openings [47]. This phenomenon is evidently seen in Figures 9 and 10, where sunlight is seen to fall directly onto indoor surfaces, resulting in a higher radiative temperature in Fgura as opposed to St Venera parish church. Given that human beings feel the operative temperature, that is, the resultant temperature derived from air temperature, radiant temperature and air speed, occupants in the Fgura parish church are expected to have a warmer thermal perception due to the direct solar radiation. 


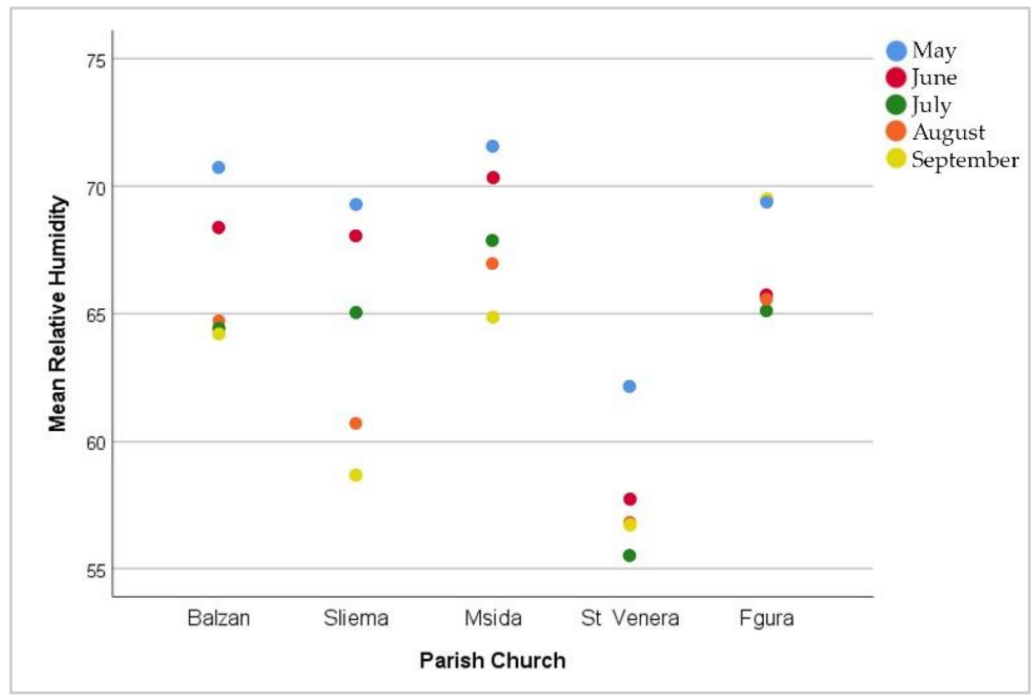

$\mathrm{F}(4,3715)=368.58, p<0.001$ (May-Relative Humidity)

$\mathrm{F}(4,595)=571.85, p<0.001$ (June-Relative Humidity)

$\mathrm{F}(4,3715)=330.18, p<0.001$ (July-Relative Humidity)

$\mathrm{F}(4,3715)=407.34, p<0.001$ (August-Relative Humidity)

$\mathrm{F}(4,3595)=399.02, p<0.001$ (September-Relative Humidity)

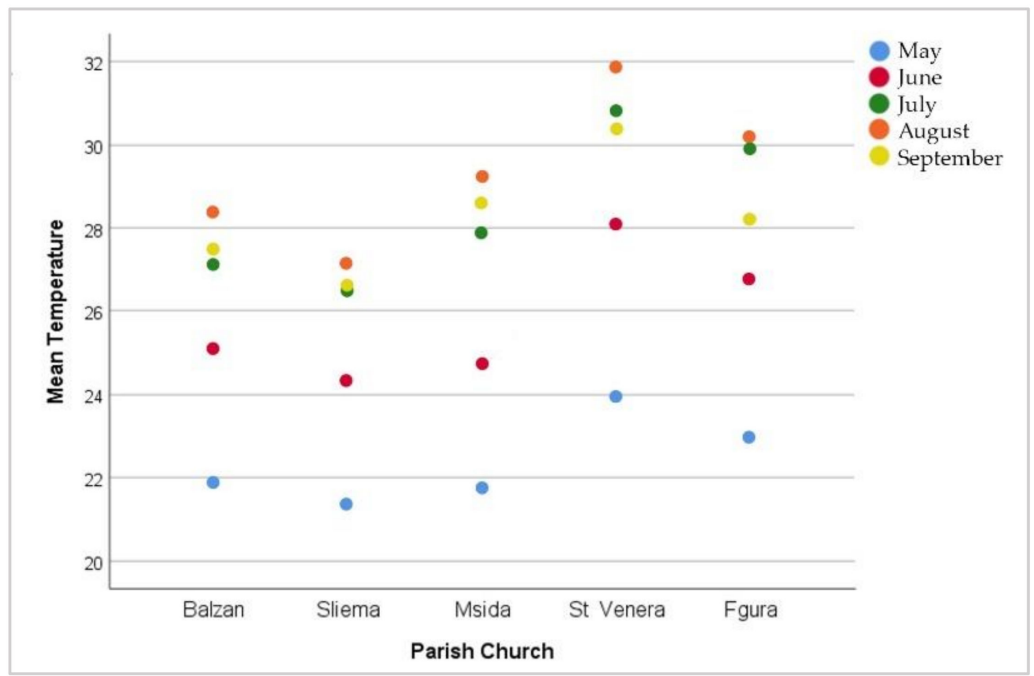

$\mathrm{F}(4,3715)=402.1, p<0.001$ (May-Temperature)

$\mathrm{F}(4,595)=1891.75, p<0.001$ (June-Temperature)

$\mathrm{F}(4,3715)=1509.181, p<0.001$ (July-Temperature)

$\mathrm{F}(4,3715)=2437.4, p<0.001$ (August-Temperature)

$\mathrm{F}(4,3595)=605.03, p<0.001$ (September-Temperature)

Figure 8. X-Y Scatter graphs depicting monthly mean relative humidity and monthly mean temperature of the parish churches in the summer. 

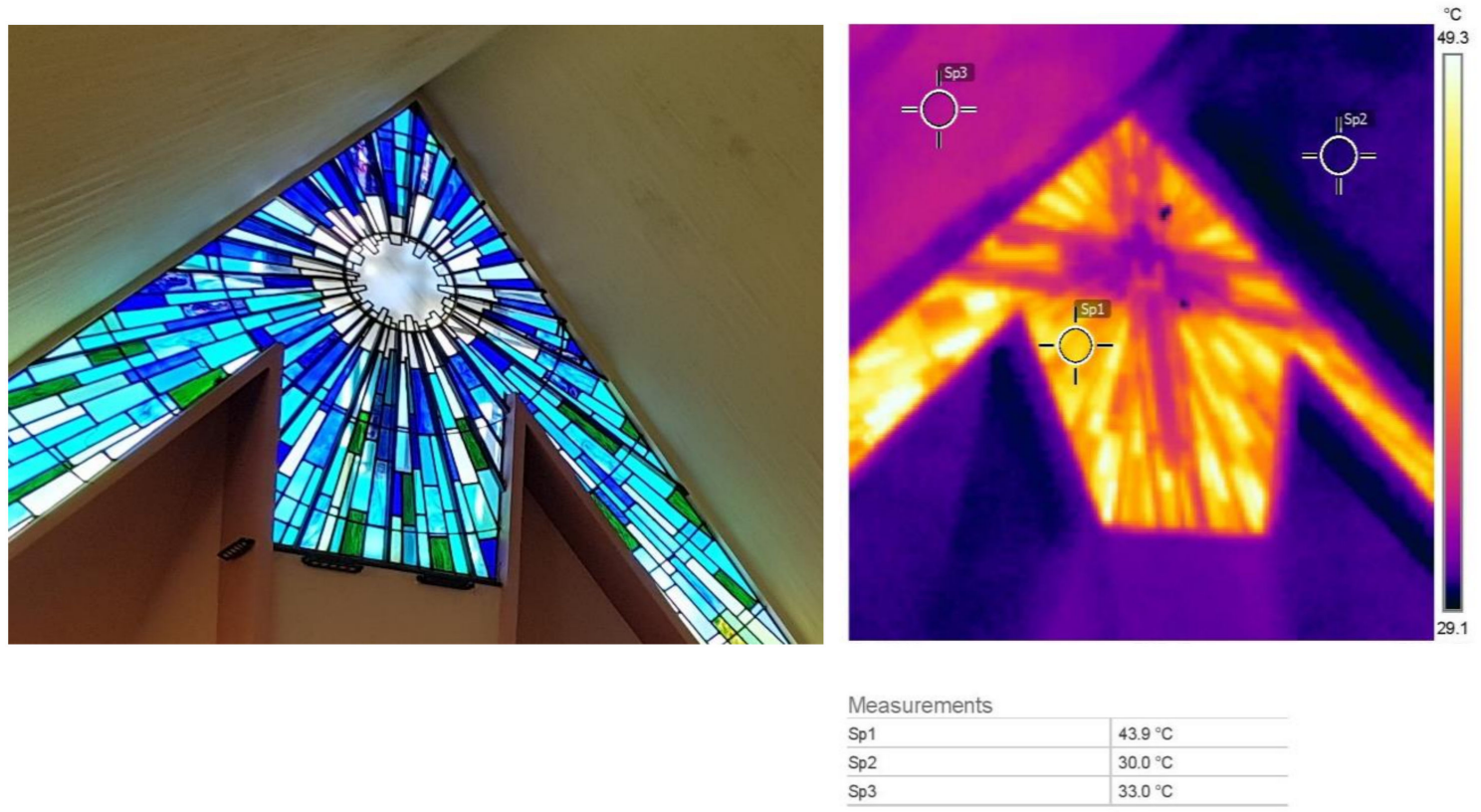

(a)

(b)

Figure 9. (a) Direct solar radiation falling onto indoor surfaces in the Fgura parish church. (b): Solar radiation transmittance through the building. Envelope of Fgura parish church: reinforced concrete-Sp1 and Sp2; stained glass-Sp3.
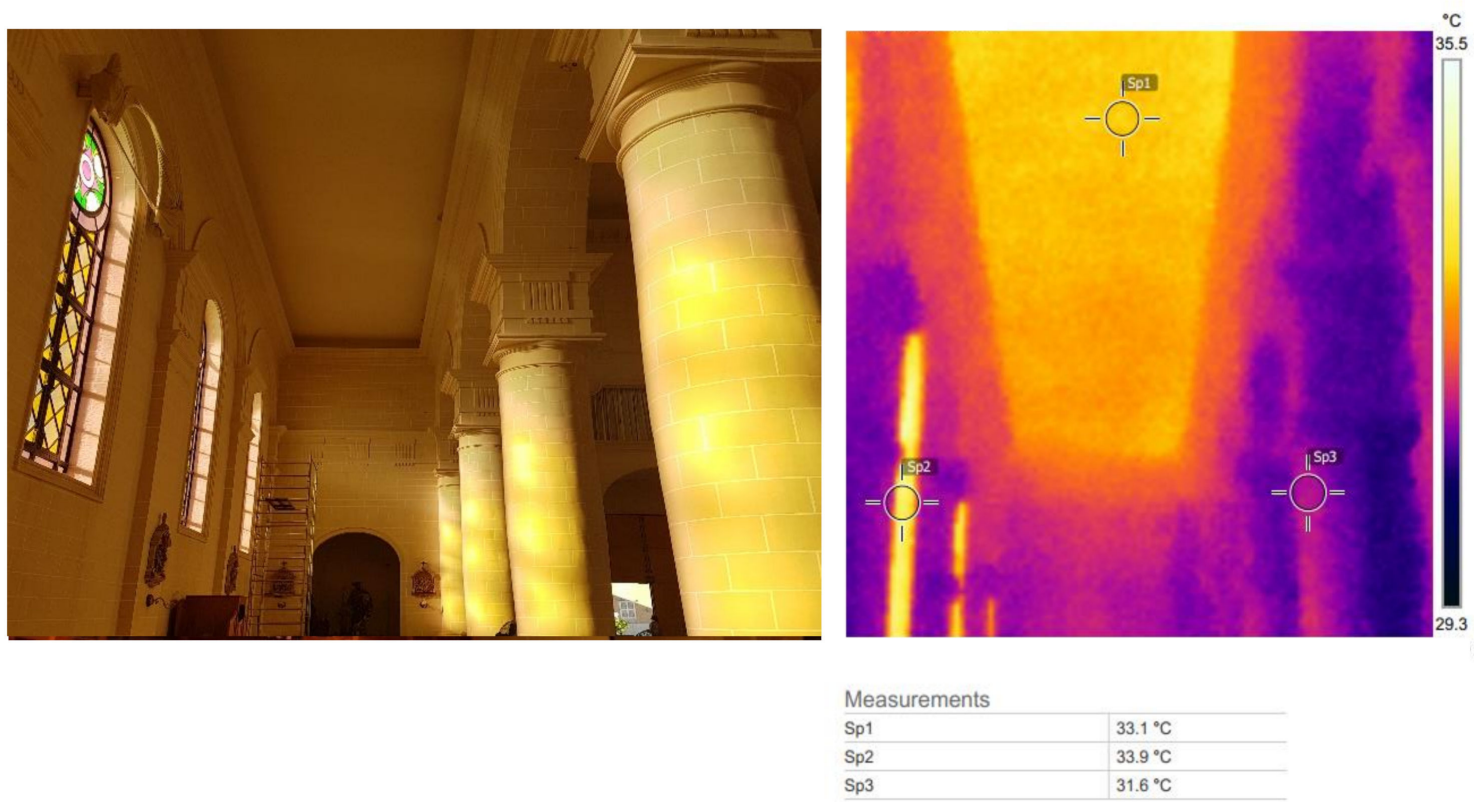

(a)

(b)

Figure 10. (a): Direct solar radiation falling onto indoor surfaces in the Santa Venera parish church. (b): Solar radiation transmittance through the building. Envelope of Santa Venera parish church: prefabricated pre-cast planks-Sp1; stained glass-Sp2; masonry column with concrete infill-Sp3.

\subsubsection{Winter}

According to the survey results, an unexpected trend is shown in Figure 11 where the thermal sensation of the interviewees in Balzan differed from those of the other two Baroque churches. It was expected that results prove a higher degree of 'neutral' voting such as that of Sliema and Msida Baroque parish churches. The reason for this anomaly could have been caused by other confounding factors such as relative humidity and indoor temperature. 


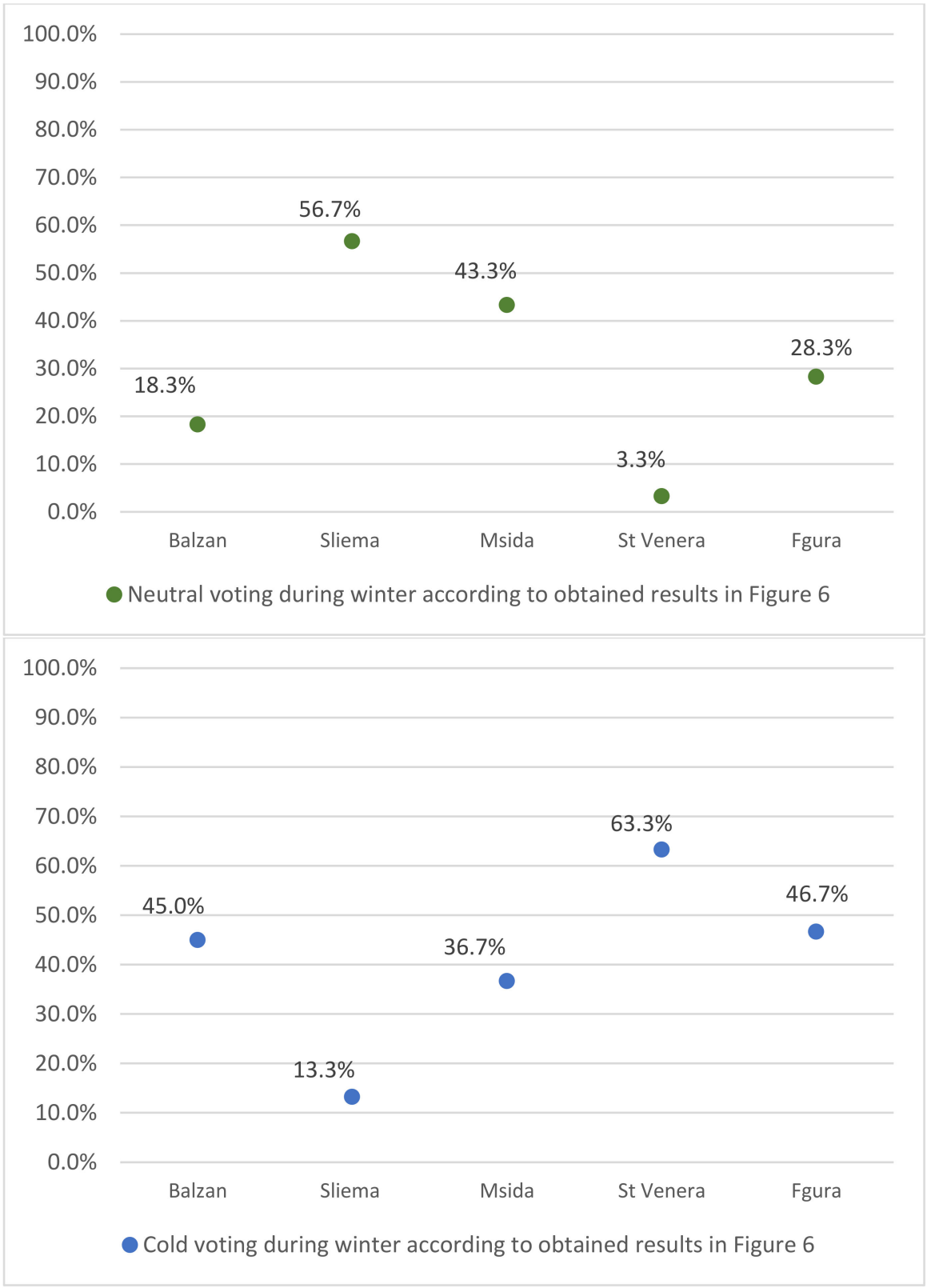

Figure 11. X-Y Scatter graphs showing the comfort level in accordance with the results obtained in Figure 6 during the winter.

In fact, Figure 12 clearly indicates that the Balzan Parish church had a high percentage of mean relative humidity and a relatively lower mean indoor temperature when compared to the other Baroque parish churches in the winter. Building moisture readings at a height of $0.5 \mathrm{~m}$ from the finished floor level revealed high humidity levels due to rising damp (refer to Table 1). This rising damp (4\%) is mainly attributed to the fact that, apart from having an underground water reservoir under the parvis, it is the only church out of all the five RBs that has an extensive abandoned subterranean crypt. This high relative humidity is further aggravated by the fact that the percentage of glazed area openings in the Balzan parish church is $0 \%$, thus minimizing the air exchanges and resulting in a constant level of high relative humidity. Likewise, Table 1 shows that the Msida parish church revealed a high percentage $(3.7 \%)$ of building moisture evident through rising damp. This high percentage of building moisture is attributed to the fact that Msida is a harbour town in East Malta, where the lower part lies at the outlet of a valley and the land in front of the 
parish church is reclaimed. At the time of building the church, no humidity barrier was incorporated in the construction of its walls.

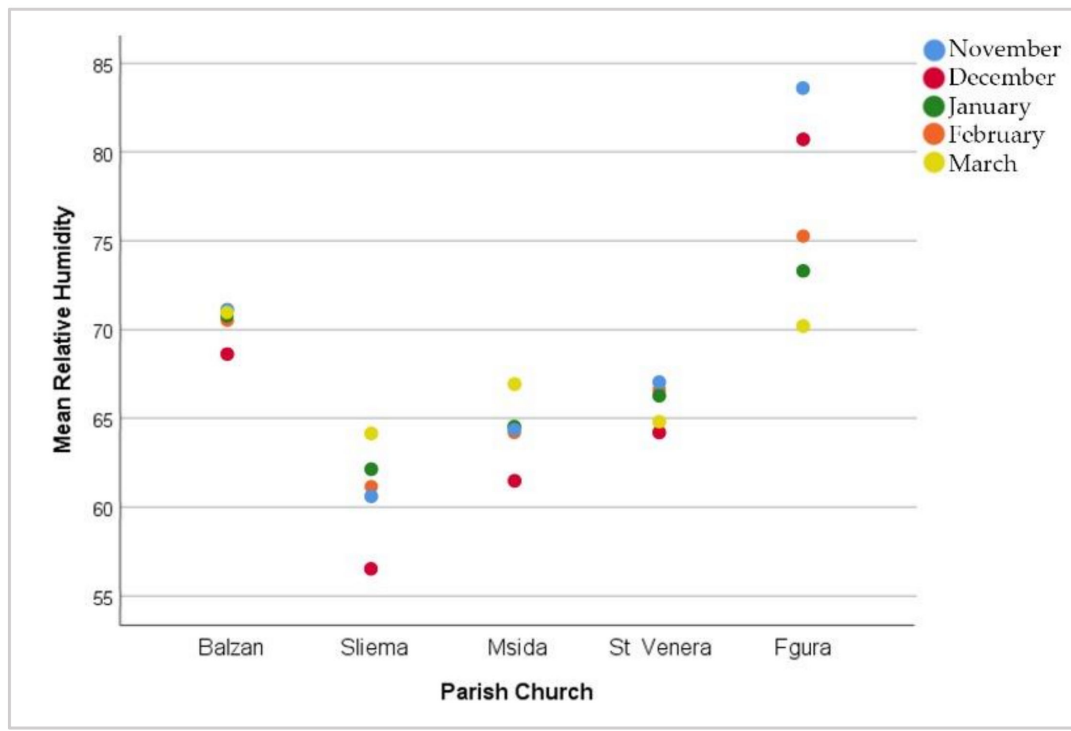

$\mathrm{F}(4,3595)=1635.07, p<0.001$ (November-Relative Humidity)

$\mathrm{F}(4,3525)=1820.09, p<0.001$ (December-Relative Humidity)

$\mathrm{F}(4,3715)=564.93, p<0.001$ (January-Relative Humidity)

$\mathrm{F}(4,3355)=754.09, p<0.001$ (February-Relative Humidity)

$\mathrm{F}(4,3715)=235.49, p<0.001$ (March-Relative Humidity)

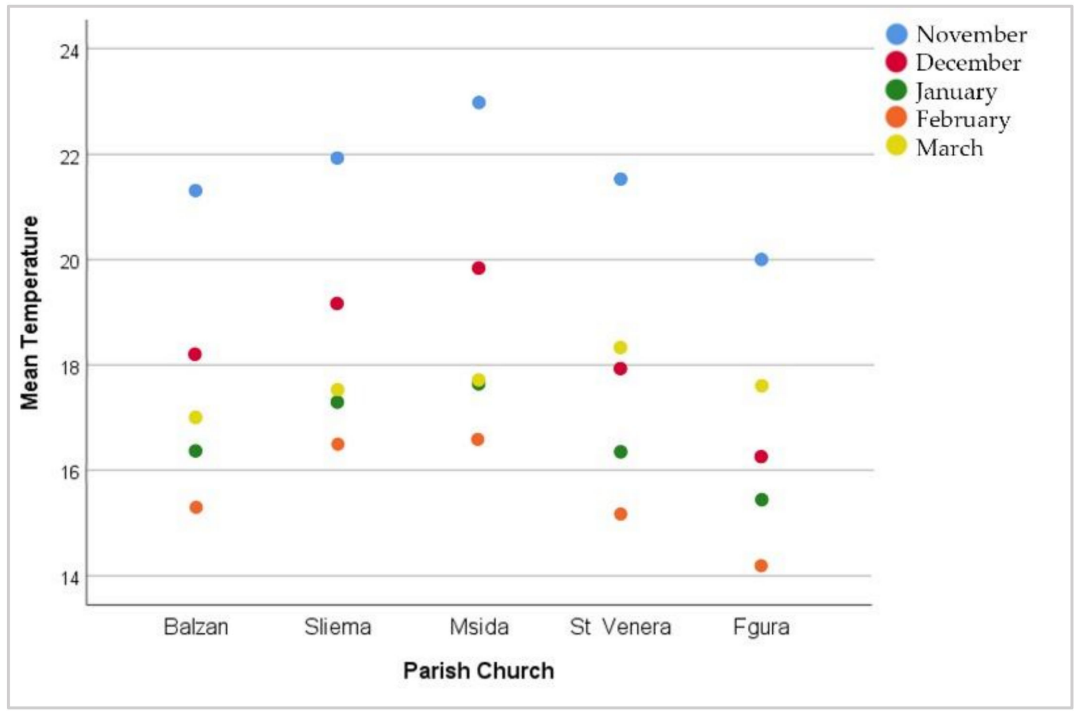

$\mathrm{F}(4,3595)=520.26, p<0.001$ (November-Temperature)

$\mathrm{F}(4,3525)=1020.57, p<0.001$ (December-Temperature)

$\mathrm{F}(4,3715)=686.27, p<0.001$ (January-Temperature)

$\mathrm{F}(4,3355)=709.03, p<0.001$ (February-Temperature)

$\mathrm{F}(4,3715)=109.93, p<0.001$ (March-Temperature)

Figure 12. $X-Y$ Scatter graphs depicting monthly mean relative humidity and monthly mean temperature of the parish churches in the winter. 
Table 1. Reference values for humidity expressed in percent by weight at 0.5-metre height of masonry wall from finished floor level (FFL).

\begin{tabular}{ccc}
\hline Church & Measuring Range (0.0-4.1\%) & \\
\hline Balzan & $4.0 \%$ & $<0.5 \%$-Dry \\
Sliema & $1.0 \%$ & $0.5-1 \%$-Borderline \\
Msida & $3.7 \%$ & $>1 \%$-Too humid \\
St Venera & $0.7 \%$ & \\
Fgura & $0.0 \%$ & \\
\hline
\end{tabular}

In the contemporary parish churches, the St Venera parish church had a higher percentage of 'cold' votes than the Fgura parish church during the winter period. This is attributed to the difference in the building envelope. With respect to the latter, it is imperative to point out that St Venera parish church has a flat roof constructed of prefabricated concrete planks, whereas the Fgura parish church is covered by a reinforced concrete roof whose axes form a symmetrical cross. This gives the church a multifaceted exterior with an interplay of plain solid inclined triangles and stained-glass panels. The combined effect is that the Fgura parish church absorbs relatively higher amounts of solar radiation in winter, both on its roof as well as through the inclined glazed surfaces, which favourably improves the indoor ambient conditions in winter. However, this added benefit of solar gains is ephemeral as at night it is re-radiated through the building's envelope [48].

On the other hand, the window-to-wall ratio of the St Venera parish church is significantly lower than that of the Fgura parish church, with a calculated percentage of $11 \%$ on the south-east and north-east facades with respect to St Venera parish church and $18 \%$ on all facades with respect to Fgura parish church. Thus, in conformity to the phenomena of the U-value explained by A. Lymath (2015) [49], there is a higher degree of heat transfer through the glazing system of the Fgura parish church, resulting in an overall more thermally comfortable environment.

\subsection{Physiological Factors-Gender}

The total study population consisted of a relatively equal number of male $(48.5 \%)$ and female (51.5\%) participants.

Overall, the results obtained from Figure 13 for summer suggest that at higher temperatures, females tolerated them more than males with $45 \%$ and $35 \%$, respectively, voting for 'neutral'. Y. Zhai et al. (2014) concluded that males tended to be more dissatisfied in warm temperatures when compared to females [50]. Moreover, B. Kingma (2015) concluded that females were more comfortable at temperatures that were 2.5 degrees Celsius higher, hence preferring warmer temperatures [51].

On the other hand, the scenario was different in winter with $25 \%$ and $28 \%$ of females and males, respectively, voting for 'neutral', indicating that, overall, both genders were comfortable in lower temperatures.

$$
\begin{gathered}
X^{2}(12)=66.75, p<0.001 \text { (Summer-male) } \\
X^{2}(12)=63.54, p<0.001 \text { (Summer-female) } \\
X^{2}(12)=49.69, p<0.001 \text { (Winter-male) } \\
X^{2}(12)=42.90, p<0.001 \text { (Winter-female) }
\end{gathered}
$$

where the number in brackets is the degrees of freedom $(\mathrm{df}=($ Rows -1$) \times($ Columns -1$))$ and the value for $\mathrm{X}^{2}(\mathrm{df})$ is the chi-squared value. 


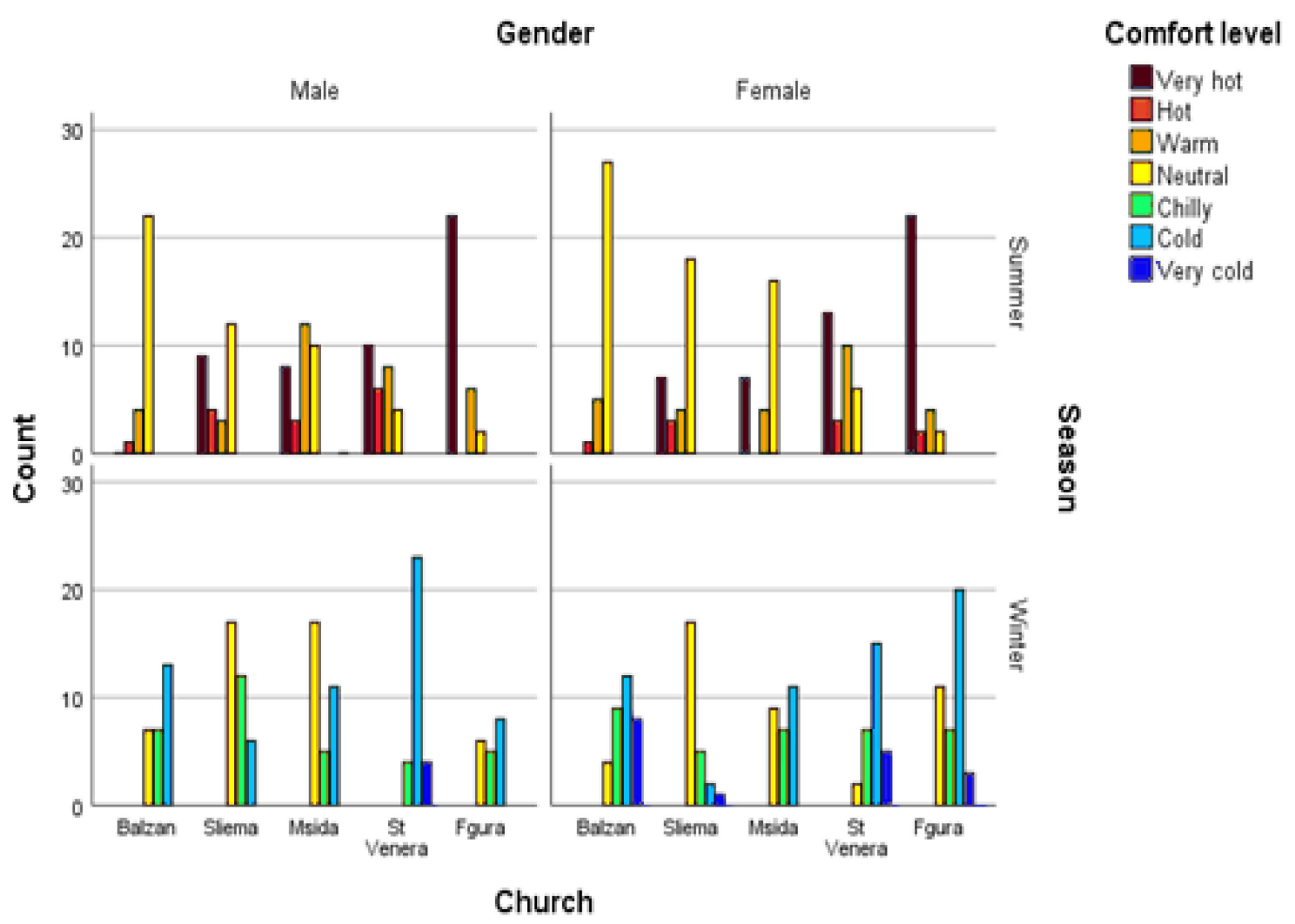

Figure 13. Bar graph representing the difference in comfort levels between males and females in the different parish churches in summer and winter.

\subsection{Physiological Factors-Age}

The age of the 600 male and female participants was also considered as a physiological factor in this study to attain a more accurate result. Age has been found to contribute to thermoregulatory mechanisms due to factors such as differences in metabolic functioning, where the older generations tend to exhibit lower body temperatures than the younger generations [52].

The study population consisted of $24 \%$ being 35 years old or less, $27 \%$ between 36 to 50 years of age, $20.3 \%$ between 51 to 60 years and the highest being $28.7 \%$ of 61 years and over, with the majority wearing light and adequate clothing in view of the high temperatures during the summer and the majority wearing multi-layered clothing during the winter.

In Figure 14, one can note that the older generations felt more thermally comfortable in hotter temperatures and less thermally comfortable in colder temperatures, when compared to the younger generations. During the summer, in the Balzan parish church there were more ' $h$ th' $^{\prime}$ and 'warm' votes coming from the younger generations (35 years or less to 50 years), whereas there were very few ' $w a r m$ ' votes coming from the older generations (51-61 years and over). In the Sliema parish church, most of the 35 years or less age group selected 'very hot' with very few voting for 'neutral'. However, as the ages increased, so did the 'neutral' votes which spiked for the oldest age group. Even though quite a few occupants also selected 'very hot', 'hot' and 'warm', the overall vote was still 'neutral'. Once again, in the St Venera parish church, most of the younger age groups (35 years or less to 50 years) voted mostly for 'very hot', 'hot' and 'warm', and although these votes were still present in the oldest age group, the 'neutral' comfort level became much more evident when compared to other age groups. With regards to the Msida and Fgura parish churches, it seems that all age groups had similar perceptions of the indoor thermal comfort level. 


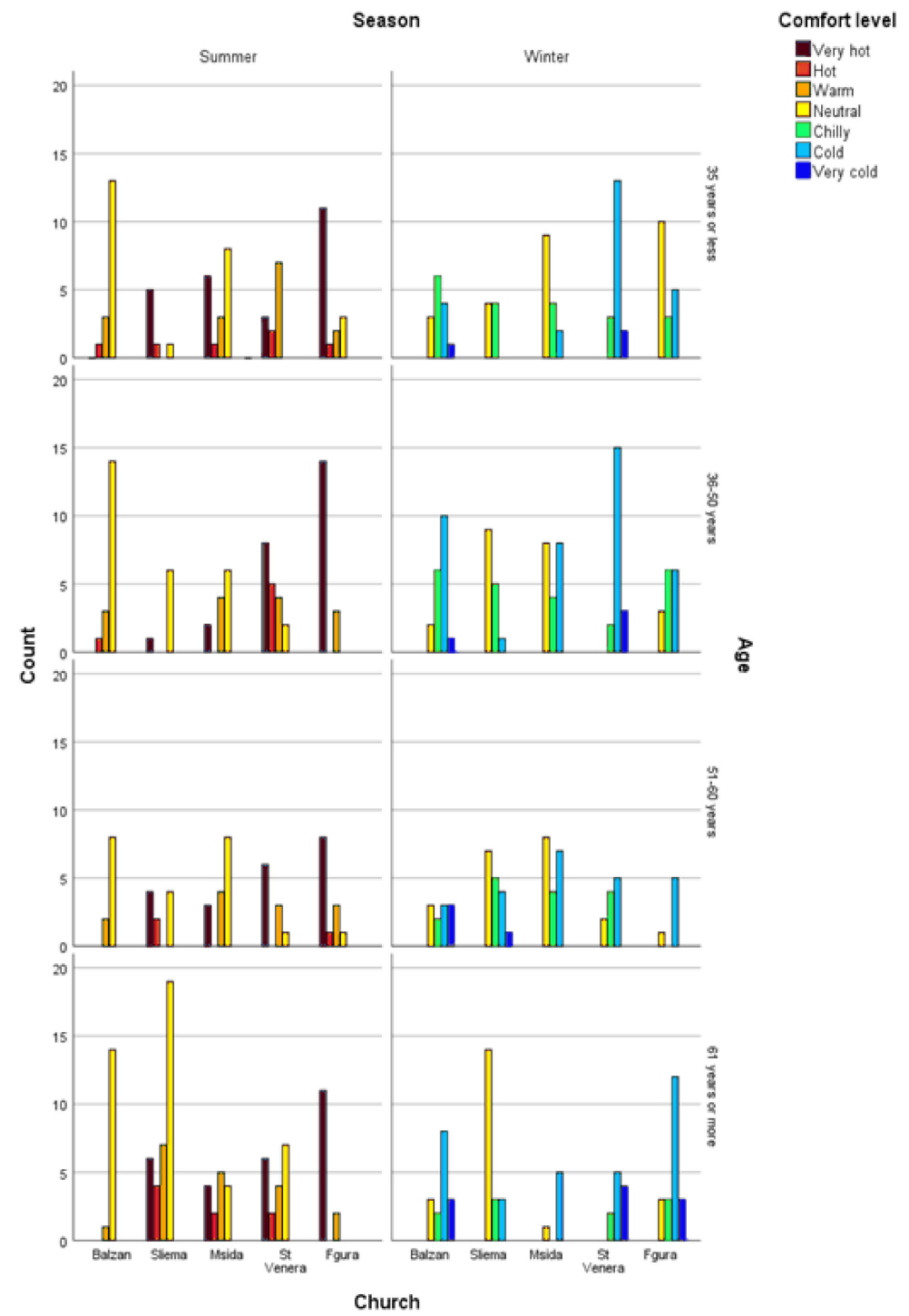

Figure 14. Column graph representing the difference in comfort levels between the four different age groups in the different parish churches in both summer and winter.

During the winter, in the Balzan parish church, 'very cold' was voted amongst the older age generations ( 51 to 61 years or more). However, this vote became less popular amongst the younger age groups ( 35 years or less to 50 years). This was also the case for the Fgura parish church, where younger generations were seen to be more thermally comfortable than the older generations since the degree of 'cold' votes was increasing from youngest to oldest. In the Msida parish church, the younger generations seemed to feel more thermally comfortable since there was a considerable number voting for 'neutral'. However, this vote decreased significantly in the oldest generation. In the Sliema parish church, it seems that occupants of all ages had similar thermal comfort perceptions as the most popular vote was 'neutral' in all age groups. On the other hand, the most popular vote for the St Venera parish church was 'cold', which was especially high in the younger generations (35 years or less to 50 years) and decreased in the older generations (51 years to 61 years or older).

Notwithstanding that the occupants participating in the TSS were not stratified by age but chosen through convenience sampling, a trend could be seen in parish churches during both the summer and winter. This corresponds to a study carried out by Blatteis, C.M et al. (2012) [52], whereby it was concluded that older generations tend to exhibit lower body temperatures, and hence, they would feel more thermally comfortable in 
warmer environments during the summer and feel more thermally uncomfortable in colder environments during the winter.

$$
\begin{gathered}
X^{2}(12)=40.41, p<0.001 \text { (Summer-35 years or less) } X^{2}(16)=50.73, p<0.001 \text { (Summer-51 to } 60 \text { years) } \\
X^{2}(12)=55.46, p<0.001 \text { (Winter-35 years or less) } X^{2}(16)=45.07, p<0.001 \text { (Winter-51 to } 60 \text { years) } \\
X^{2}(12)=28.43, p=0.005 \text { (Summer-36 to } 50 \text { years) } X^{2}(16)=48.15, p<0.001 \text { (Summer-61 years or more) } \\
X^{2}(12)=42.90, p<0.001 \text { (Winter-36 to } 50 \text { years) } X^{2}(16)=54.51, p<0.001 \text { (Winter } 61 \text { years or more) }
\end{gathered}
$$

where the number in brackets is the degrees of freedom $(\mathrm{df}=($ Rows -1$) \times($ Columns -1$))$ and the value for $\mathrm{X}^{2}(\mathrm{df})$ is the chi-squared value.

\subsection{Sources of Discomfort}

\begin{tabular}{|c|c|c|c|c|c|c|}
\hline \multirow[b]{2}{*}{ Season } & \multirow[b]{2}{*}{ Sources of Discomfort } & \multicolumn{5}{|c|}{ Parish Church } \\
\hline & & Balzan & Sliema & Msida & St Venera & Fgura \\
\hline \multirow{6}{*}{ Summer } & Too much air movement & 1 & 2 & 0 & 0 & 0 \\
\hline & Insufficient air movement & 6 & 22 & 35 & 14 & 21 \\
\hline & Direct sunlight & 21 & 3 & 2 & 33 & 33 \\
\hline & Insufficient cooling/heating & 4 & 12 & 3 & 5 & 2 \\
\hline & Irregular temperature & 1 & 0 & 0 & 1 & 1 \\
\hline & No discomfort & 27 & 21 & 20 & 7 & 3 \\
\hline \multirow{7}{*}{ Winter } & Too much air movement & 16 & 5 & 15 & 27 & 16 \\
\hline & Insufficient air movement & 9 & 0 & 2 & 0 & 2 \\
\hline & Direct sunlight & 1 & 0 & 0 & 0 & 1 \\
\hline & Ambience of church is hot/cold & 15 & 6 & 4 & 12 & 12 \\
\hline & Insufficient cooling/heating & 12 & 4 & 3 & 5 & 13 \\
\hline & Irregular temperature & 7 & 4 & 4 & 3 & 1 \\
\hline & No discomfort & 0 & 41 & 32 & 13 & 15 \\
\hline
\end{tabular}

The survey was also intended to identify the sources of discomfort. Table 2 shows the outcome of the responses.

Table 2. Showing the different sources of discomfort in the different parish churches in both summer and winter.

During the summer, most of the participants in the Balzan parish church selected 'no discomfort' (45\%). Slightly smaller percentages of participants selected this option for the Sliema (35\%) and Msida (33.3\%) parish churches. However, in the contemporary parish churches, votes for 'no discomfort' had decreased significantly with $11.7 \%$ for St Venera parish church and $5 \%$ for Fgura parish church. This result supports the findings defined in Section 3.1 that the Baroque parish churches perform better in terms of comfort during the summer. Analysing the parish churches in further detail, it can be noted that whilst during the summer the Balzan parish church ranked the highest in terms of 'no discomfort', it also had a relatively high percentage of votes for 'direct sunlight' (35\%).

The percentages of Sliema church parishioners selecting 'insufficient air movement' $(36.7 \%)$ and 'insufficient cooling/heating' $(20.0 \%)$ were amongst the largest. Although the Sliema parish church has the highest percentage of glazed area openings $(20 \%)$ when compared to Balzan ( $0 \%$ ) and Msida (3\%) parish churches, thus expecting better air movement, this is not the case. Casement windows are located in the dome, and the natural flow of air through the church due to vertical differences in temperature is not sufficient to create air circulation. The lack of air infiltration is further aggravated by closed doors, short-circuiting the stack effect ventilation of fresh air thus preventing any significant draft movement [53].

Like the Sliema parish church, the Msida parish church achieved a high percentage of votes for 'insufficient air movement' (58.3\%). This result was expected since the percentage of area openings is very low $(3 \%)$.

With regards to the contemporary churches, the Fgura parish church had a relatively high percentage of votes for 'insufficient air movement' (35\%) but an even higher percentage 
for 'direct sunlight' (55\%). Similarly, the St Venera parish church also had 'direct sunlight' as the most popular vote amongst the occupants (55\%). This spike in 'direct sunlight' voting in the contemporary parish churches when compared to the Baroque churches is mainly attributed to the fact that both contemporary churches have a high percentage of glazing (refer to Figures 9 and 10). Nevertheless, parishioners' vote for 'insufficient air movement' was still relatively high. As the overall thermal comfort level of the church was 'very hot', ventilation proved not sufficient to compensate for the overheating and direct sunlight that affected the thermal perception of the occupants.

As for the winter, 'no discomfort' ranked as the most popular vote in the Sliema parish church (68.3\%) followed by Msida (53.3\%), Fgura (25\%) and St Venera parish church (21.7\%). This result does not support the findings defined in Section 3.1. With regards to the Balzan parish church, one would expect it to have a similar thermal comfort level as the other Baroque parish churches. Nevertheless, this was not the case as findings show that there were $0 \%$ of participants voting for ' $n o$ discomfort'. However, findings resulted in an overall increase of discomfort, especially when compared to the other two Baroque churches, including 'too much air movement' (26.7\%), 'cold ambience' (25\%), 'insufficient heating' (20\%) and 'insufficient air movement' (15\%).

In this study, consideration was also given to $\mathrm{CO}_{2}$ levels within all respective parish churches. M. Kuru et al. concluded that an increased concentration of carbon dioxide $\left(\mathrm{CO}_{2}\right)$, especially in an already significantly humid area, would result in low indoor air quality and decrease the thermal comfort of such occupants [54]. The average indoor $\mathrm{CO}_{2}$ levels recorded in each parish church were within the acceptable EU recommended range of 600 to $1000 \mathrm{ppm}[55,56]$. This threshold was only exceeded for an interim period in Fgura parish church when considering readings at 5 min intervals on Sunday (refer to Figure 15). Improved ventilation rates ought to keep carbon dioxide concentration lower than $1000 \mathrm{ppm}$. Thus, the determination of indoor air quality (IAQ) levels through $\mathrm{CO}_{2}$ readings, amongst other parameters, indicates that there is no direct link between exposure to measured $\mathrm{CO}_{2}$ concentration and comfort of building occupants [57].

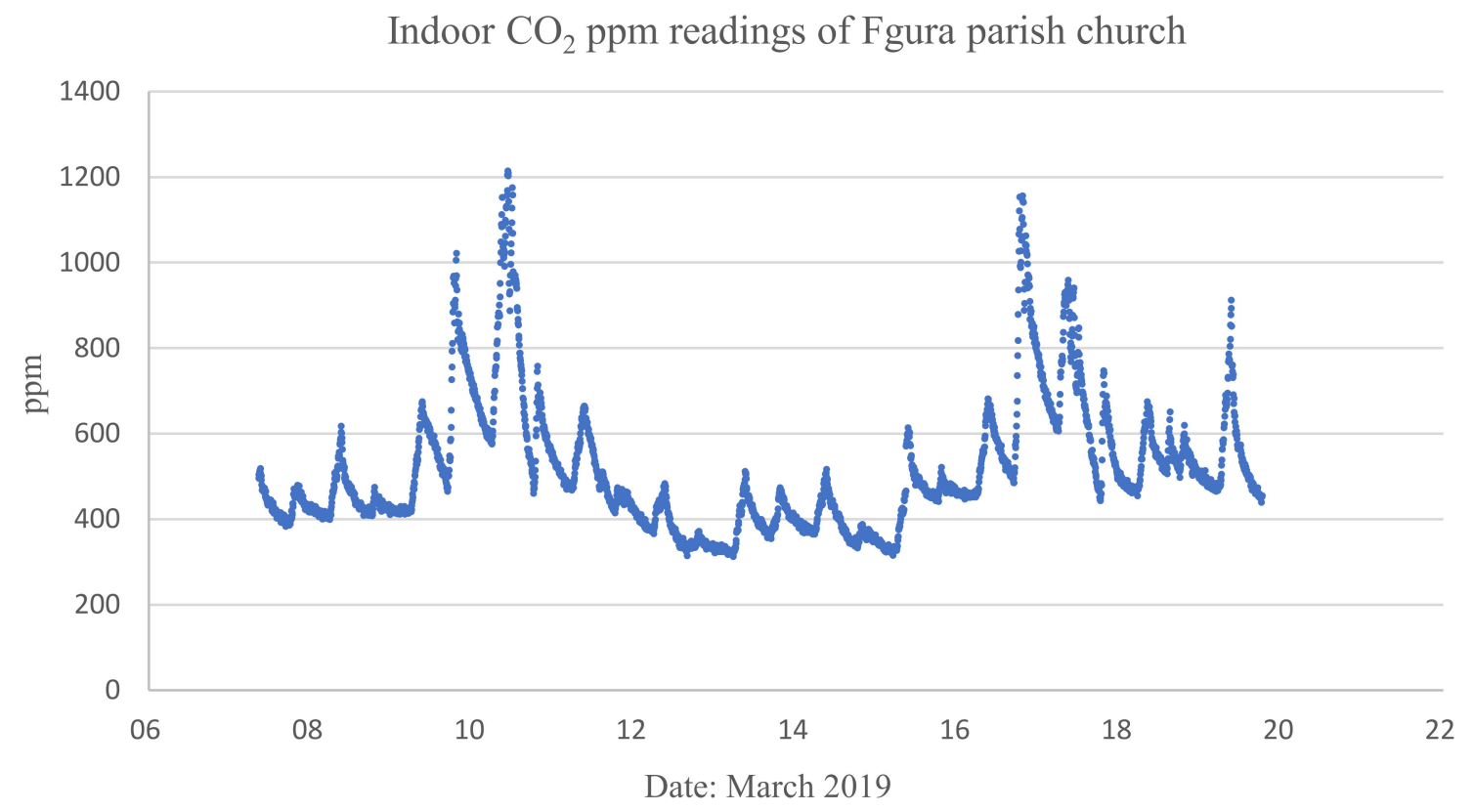

Figure 15. $\mathrm{X}-\mathrm{Y}$ Scatter graphs showing the $\mathrm{CO}_{2}$ readings of Fgura parish church.

The Balzan parish church also had a relatively high percentage voting for 'cold ambience' $(25 \%)$. This is the result of lowest indoor recorded temperatures combined with the highest percentage of indoor relative humidity. A high percentage of occupants also selected 
'insufficient heating' (20\%), possibly due to being exposed to higher quality of thermally controlled environments [58].

Further analysis of the results displayed in Table 2 showed that votes for 'no discomfort' spiked up to a total of $68.3 \%$ in the Sliema parish church with an insignificant degree of votes for other sources of discomfort, all of which ranked below $2 \%$. Sliema parish church also proved to have the lowest recorded indoor relative humidity, whilst maintaining a thermally comfortable indoor temperature [59] and good indoor air quality due to air movement and ventilation. One must take into consideration the fact that Sliema parish church had the largest percentage (33.3\%) of parishioners over 61 years when compared to the other Baroque churches under study. Similar results were attained in the Msida parish church with a slight decrease in 'no discomfort' voting (53.3\%) and a slight increase in 'too much air movement' (25\%).

The results obtained for the contemporary churches are as anticipated. The indoor air temperature results have already shown that the overall indoor thermal comfort is relatively low when compared to the Baroque churches.

$$
\begin{gathered}
X^{2}(20)=120.34, p<0.001 \text { (Summer) } \\
X^{2}(24)=127.47, p<0.001 \text { (Winter) }
\end{gathered}
$$

where the number in brackets is the degrees of freedom $(\mathrm{df}=($ Rows -1$) \times($ Columns -1$))$ and the value for $\mathrm{X}^{2}(\mathrm{df})$ is the chi-squared value.

Source of discomfort voting for 'too much air movement' (45\%), followed by 'cold ambience' $(20 \%)$, was recorded highest for the St Venera parish church. This results from the lack of a porch (known in Maltese as an antiporta), causing substantial indoor fluctuations during service hours. It is pertinent to point out that out of the five selected churches, St Venera parish church is the only church that does not have an antiporta.

Similar results were attained in the Fgura parish church however with fewer votes for 'too much air movement' (26.7\%) and more votes for 'insufficient heating' $(21.7 \%)$. This difference in percentages is mainly attributed to significantly higher percentage of relative humidity together with lower indoor recorded temperatures, which in turn results in an overall cooler indoor ambience.

\subsection{Suggestions from Parishioners}

According to Table 3, suggestions taken during the summer once again confirmed that the Balzan parish church was the most thermally comfortable out of all the parish churches under study since most of its parishioners selected 'no suggestion' $(81.7 \%)$, as shown in Column 1 of Table 3 (Qty. 49). Only nine votes were registered suggesting an 'air-conditioner'. It is pertinent to point out that Balzan parish church, such as that of Sliema, has already installed an air-conditioning system. This was intermittently operational on the day the TSS was conducted in Balzan, resulting in cooler temperatures and more comfortable indoor conditions. The fact that some parishioners still suggested the use of 'air-conditioning' may be attributed to the need for more frequent use, lower set temperatures or better positioning of the indoor units.

On the other hand, votes for the 'air-conditioner' were more pronounced in the Sliema parish church with a total of 36.7\%, as shown in Column 2 of Table 3 (Qty. 22). It is pertinent to point out that although Sliema parish church is equipped with an air-conditioning system, this was not operational on the day of the TSS. Nonetheless, a number of occupants still felt that the overall ambience of the church was thermally comfortable since a total of $46.7 \%$ votes (Qty. 28) were given to 'no suggestion'. This is in accordance with the findings portrayed in Figure 6, whereby Sliema ranked as being the second most thermally comfortable out of the Baroque parish churches under review. On the other hand, the main sources of discomfort were 'insufficient air movement' and 'insufficient cooling'. This explains why occupants felt the need to vote for making use of air conditioners, which though installed are only used occasionally. 
Table 3. Showing the different suggestions in the different parish churches in both summer and winter.

\begin{tabular}{|c|c|c|c|c|c|c|}
\hline \multirow[b]{2}{*}{ Season } & \multirow[b]{2}{*}{ Suggestions } & \multicolumn{5}{|c|}{ Parish Church } \\
\hline & & Balzan & Sliema & Msida & St Venera & Fgura \\
\hline \multirow{5}{*}{ Summer } & Curtains/blinds & 0 & 1 & 0 & 22 & 1 \\
\hline & Air-conditioner & 9 & 22 & 15 & 11 & 30 \\
\hline & Open windows/doors & 0 & 0 & 9 & 0 & 0 \\
\hline & Fans & 2 & 9 & 17 & 6 & 17 \\
\hline & No suggestion & 49 & 28 & 19 & 21 & 12 \\
\hline \multirow{5}{*}{ Winter } & Heaters & 23 & 11 & 8 & 16 & 30 \\
\hline & Curtains/blinds & 2 & 0 & 0 & 0 & 2 \\
\hline & Dehumidifier & 20 & 2 & 4 & 4 & 0 \\
\hline & Close windows/doors & 15 & 2 & 8 & 20 & 0 \\
\hline & No suggestion & 0 & 45 & 40 & 19 & 28 \\
\hline
\end{tabular}

The Msida parish church ranked just below St Venera parish church in terms of 'no suggestion' with a total of $31.7 \%$ and 35\%, respectively, as shown in Columns 3 and 4 of Table 3 (Qtys. 19 and 21). This result deviates significantly from the established ranking of indoor thermal comfort (refer to Figure 6), where the Msida parish church showed to be much more thermally comfortable than the St Venera parish church. However, when it came to the sources of discomfort, the Msida parish church had a significantly greater number of votes for 'insufficient air movement' than the St Venera parish church, which explains why many occupants selected 'fans' $(28.3 \%)$ and 'air conditioner' $(25 \%)$ in their suggestions. Moreover, it must be noted that only $3 \%$ of glazing area openings were being used in the Msida parish church, which further explains why quite a considerable number of occupants also opted for 'open windows/doors' (15\%).

Out of the contemporary parish churches, the St Venera parish church had more votes for 'no suggestion' than the Fgura parish, with votes ranging from $35 \%$ to $20 \%$, respectively. Once again, St Venera parish church ranked as being more thermally comfortable.

With regards to the suggestions given by parishioners, the St Venera parish church had a significantly high percentage of occupants voting for 'curtains/blinds' $(36.7 \%)$ and much fewer votes for 'air-conditioner' (18.3\%) and 'fans' (10\%), as shown in Columns 4 and 5 of Table 3. On the contrary, the suggestions for 'air-conditioner' (50\%) and 'fans' $(28.3 \%)$ spiked in the Fgura parish church, whereas votes for 'curtains/blinds' (1.7\%) were insignificant. The reason behind this result is associated with the fact that curtains/blinds are not practical for triangular-shaped inclined apertures, such as those of the Fgura parish church. In fact, though the latter has a higher window-to-wall ratio when compared to the St Venera parish church and thus is exposed to a higher degree of sunlight, votes for curtains/blinds were close to none. Hence, installing air conditioners or fans was seen to be a more practical solution for this church. Contrastingly, the St Venera parish church's glazing design is traditional to the Maltese urban landscape, and therefore installing vertical curtains/blinds was seen by most occupants as a feasible solution.

In winter, the ranking of 'no suggestion' (refer to Table 3) voting of all the parish churches portrays a similar trend to the obtained results in thermal comfort ranking (refer to Figure 6) and sources of discomfort (refer to Table 2).

In the Balzan parish church, there were no votes for 'no suggestions' and a greater percentage of votes for 'heaters' (38.3\%), 'dehumidifiers' (33.3\%) and 'close windows/door' $(25 \%)$, as shown in Column 1 of Table 3. These results are in tandem and correlate with other findings in this regard. Since the Balzan parish church has a very high percentage of indoor relative humidity and a low indoor temperature, with the highest values for humidity in the masonry walls due to rising damp out of all RBs (refer to Table 1), the overall thermal ambience of the church is cold and humid. Thus, votes for heaters and dehumidifiers to be installed in the church are coherent. Moreover, parishioners stated that there was a relatively high degree of 'too much air movement' (26.7\%) within the church, which explains why $25 \%$ of occupants selected 'closed windows/door'. 
The Sliema parish church had the highest percentage for 'no suggestion' $(75 \%)$ and a few votes for 'heaters' (18.3\%), as shown in Column 2 of Table 3. This reflects the fact that this church is overall thermally comfortable with very few occupants stating otherwise. Similarly, the Msida parish church also had a high percentage of votes for 'no suggestion' (66.7\%) followed by fewer votes for 'heaters' (13.3\%), 'close windows/doors' $(13.3 \%)$ and 'dehumidifier' (6.7\%), as shown in Column 3 of Table 3. This result confirms that the Msida parish church is also overall thermally comfortable, with minimal non-invasive intervention, such as closing windows/doors proving sufficient.

The St Venera parish church had the lowest 'no suggestion' voting (31.7\%) out of the contemporary churches. Moreover, $33.3 \%$ of its occupants selected 'close windows/doors'. This correlates with the high percentage achieved for 'too much air movement' as a result of the missing antiporta, conceivably further aggravating the cold ambiance of the church, for which $20 \%$ of the occupants voted as 'cold ambience'. Coherently, $26.6 \%$ of the occupants selected 'heaters' to rectify.

The results for the Fgura parish church were similar to those of the St Venera parish church, with an increase in votes for 'no suggestion' (46.7\%) and 'heaters' (50\%). This may be attributed to the fact that there is a significantly higher percentage of indoor relative humidity and a low indoor temperature, hence creating an overall colder environment.

$$
\begin{gathered}
X^{2}(16)=178.98, p<0.001 \text { (Summer) } \\
X^{2}(16)=177.83, p<0.001 \text { (Winter) }
\end{gathered}
$$

where the number in brackets is the degrees of freedom $(\mathrm{df}=($ Rows -1$) \times($ Columns -1$))$ and the value for $\mathrm{X}^{2}(\mathrm{df})$ is the chi-squared value.

\section{Conclusions}

Results attained through mathematical statistics from thermal sensation surveys, recorded indoor temperature and relative humidity conclude that a significant correlation exists between the actual thermal comfort levels measured according to EN 16798-1 standard and that expected by the occupants in most of the parish churches under evaluation for both summer and winter.

Baroque churches were found to be overall more thermally comfortable than the contemporary churches in both summer and winter due to their differences in construction methodology and building envelope. Moreover, the difference between indoor radiant and air temperatures was found to be insignificant.

With regards to physiological factors taken into consideration, results show that females tend to feel more thermally comfortable than males in warmer climates and that older generations tend to feel more thermally comfortable in warmer rather than colder environments.

A number of parishioners recommended mechanical means of air-conditioning to improve the thermal ambience in both summer and winter. The use of a combination of natural and mechanical ventilation may improve the adaptation conditions of occupants. However, though a hybrid system could be considered, one must be concerned about the consequences of this decision, such as energy costs, its effect on building material and artefacts and its carbon footprint. It is understandable that today's comfort expectations have increased significantly; however, it must also be appreciated that the use of places of worship is mainly intermittent and air-conditioning systems may not always be justified.

The use of passive measures through better use of operable apertures and shading was also strongly highlighted by parishioners. These mainly referred to feasible options to optimise on orientation in controlling solar gains, natural ventilation and the effective use of the building envelope to decrease extreme internal temperatures. Based on the human interaction with the built environment, these suggested passive measures, which have the potential to satisfy comfort expectations and are critical to achieving a lifetime of thermal comfort, should first be considered prior to any mechanical means. 
This true understanding of occupants' thermal comfort requirements provides unprecedented first-hand information about occupants' diversities of thermal sensations and dynamic behaviour adaptations to the intricate environment within churches. Analysis of the sources of discomfort and suggestions made by the occupants' revealed how passive design solutions help enhance indoor thermal conditions, within issues portrayed, while reducing energy demands and eventually carbon emissions. This information provides assurance for optimised decision-making methods, used to generate accurate solutions for policy-makers, architects and engineers, with an understanding of practical applications of passive measures for places of worship.

\section{Limitations}

Whilst these RBs served as typical buildings to represent differences between Baroque and contemporary parish churches, it is pertinent to point out that the outcome might not be applicable to all parish churches on the Maltese islands.

Author Contributions: Conceptualization, R.C.V. and C.Y.; methodology, R.C.V., C.Y. and L.C.; software, R.C.V. and L.C.; validation, R.C.V., C.Y. and F.J.R.M.; formal analysis, R.C.V., C.Y. and L.C.; investigation, R.C.V. and C.Y.; resources, R.C.V. and C.Y.; data curation, R.C.V., C.Y. and L.C.; writing - original draft preparation, R.C.V.; writing—review and editing, R.C.V., F.J.R.M., C.Y. and L.C.; visualization, R.C.V.; supervision, F.J.R.M. and C.Y.; project administration, R.C.V. and C.Y.; funding acquisition, R.C.V. All authors have read and agreed to the published version of the manuscript.

Funding: This research did not receive any specific grant from funding agencies in the public, commercial or not-for-profit sectors.

Institutional Review Board Statement: Ethical review and approval were waived for this study, due to anonymous collection of data and all participants were over 18 years old.

Informed Consent Statement: Informed consent was obtained from all subjects involved in the study.

Data Availability Statement: Not applicable.

Acknowledgments: The authors would like to acknowledge the ecclesiastical authorities for providing the necessary permissions and support to conduct this study, in particular the Archbishop's Curia, the Order of the Brothers of the Most Blessed Virgin Mary of Mt. Carmel and the Parish Priests of the respective churches. Special thanks go to the Institute for Sustainable Energy of the University of Malta for providing the necessary monitoring equipment for this study and to the Departamento Ingeniería Energética y Fluidomecánica, Escuela de Ingenierías Industriales of the Universidad de Valladolid, Spain, for their support. MDPI encourages written permission from acknowledged individuals because acknowledgment may imply endorsement.

Conflicts of Interest: The authors declare no conflict of interest.
Abbreviations
RB Reference Building
TSS Thermal Sensation Survey
CTS Current Thermal State

\section{References}

1. Caruana, C. Mass Attendance Set to Collapse in the Years to Come. 2019. Times of Malta. Available online: https://timesofmalta. com/articles/view/mass-attendance-set-to-collapse-in-the-years-to-come.700305 (accessed on 1 February 2019).

2. Environment and Resources Authority (ERA). State of the Environment Report; Environment and Resource Authority: Marsa, Malta, 2018; Available online: https:/ / era.org.mt/topic/soer/ (accessed on 12 March 2019).

3. Luo, M. The Dynamics and Mechanism of Human Thermal Adaptation in Building Environment; Springer: Berlin/Heidelberg, Germany, 2020. [CrossRef]

4. Li, B.; Li, W.; Liu, H.; Yao, R.; Tan, M.; Jing, S.; Ma, X. Physiological expression of human thermal comfort to indoor operative temperature in the non-HVAC Environment. Indoor Built Environ. 2010, 19, 221-229.

5. Liu, J.; Yao, R.; McCloy, R. An investigation of thermal comfort adaptation behaviour in office buildings in the UK. Indoor Built Environ. 2013, 23, 675-691. [CrossRef] 
6. Yao, R.; Costanzo, V.; Li, X.; Zhang, Q.; Li, B. The effect of passive measures on thermal comfort and energy conservation. A case study of the hot summer and cold winter climate in the Yangtze River region. J. Build. Eng. 2018, 15, 298-310. [CrossRef]

7. Schnieders, J.; Feist, W.; Rongen, L. Passive houses for different climate zones. Energy Build. 2015, 105, 71-87. [CrossRef]

8. Consoli, A.; Costanzo, V.; Evola, G.; Marletta, L. Refurbishing an existing apartment block in Mediterranean climate: Towards the passivhaus standard. Energy Procedia 2017, 111, 397-406. [CrossRef]

9. Energy Performance of Buildings Directive (EU) 1018/844. Available online: https:/ / eur-lex.europa.eu/legal-content/EN/TXT/ PDF/?uri=CELEX:32018L0844\&from=EN (accessed on 23 August 2020).

10. Passive and Low Energy Architecture PLEA 2020-First Virtual PLEA Conference. 2020. Available online: http:/ / www.pleaarch.org/index.php/plea-2020-first-virtual-plea-conference/ (accessed on 15 March 2020).

11. Casadevall, A. Climate change brings the specter of new infectious diseases. J. Clin. Investig. 2020, 130, 553-555. [CrossRef]

12. Ballarini, I.; Corgnati, S.P.; Corrado, V. Use of reference buildings to assess the energy saving potentials of the residential building stock: The experience of TABULA project. Energy Policy 2014, 68, 273-284. [CrossRef]

13. Climate in Malta. Weather and Climate. 2018. Available online: https://weather-and-climate.com/average-monthly-RainfallTemperature-Sunshine,Malta (accessed on 28 December 2020).

14. Fanger, P.O. Thermal Comfort Analysis and Applications in Environmental Engeering; Danish Technical Press: Copenhagen, Denmark, 1972.

15. Ghosh, O. Comfort Band in Hot and Humid Climates; Architectural Association School of Architecture, Architectural Association Graduate School: London, UK, 2015.

16. Vellei, M.; Herrera, M.; Fosas, D.; Natarajan, S. The influence of relative humidity on adaptive thermal comfort. Build. Environ. 2017, 124, 171-185. [CrossRef]

17. Corgnati, S.P.; Fabrizio, E.; Filippi, M.; Monetti, V. Reference buildings for cost optimal analysis: Method of definition and application. Appl. Energy 2013, 102, 983-993. [CrossRef]

18. Frontczak, M.; Wargocki, P. Literature survey on how different factors influence human comfort in indoor environments. Build. Environ. 2011, 46, 922-937. [CrossRef]

19. Karyono, T.H. The relationship between building design and indoor temperatures: A case study in three different buildings in Indonesia. In Proceedings of the 6th Windsor Conference Adapting to Change: New Thinking on Comfort, Windsor, UK, 9-11 April 2010.

20. Lotfabadi, P.; Hançer, P. A Comparative Study of traditional and contemporary building envelope construction techniques in terms of thermal comfort and energy efficiency in hot and humid climates. Sustainability 2019, 11, 3582. [CrossRef]

21. Mishra, A.K.; Ramgopal, M. Field studies on human thermal comfort-An overview. Build. Environ. 2013, 64, 94-106. [CrossRef]

22. Van Hoof, J. Forty years of Fanger's model of thermal comfort: Comfort for all? Indoor Air 2008, 18, 182-201. [CrossRef] [PubMed]

23. Rupp, R.; Vasquez, N.G.; Lamberts, R. A review of human thermal comfort in the built environment. Energy Build. 2015, 105, 178-205. [CrossRef]

24. Kottek, M.; Grieser, J.; Beck, C.; Rudolf, B.; Rubel, F. World map of the Köppen-Geiger climate classification updated. Meteorol. Z. 2006, 15, 259-263. [CrossRef]

25. Malta International Airport. Malta Basks on Over 363 Hours of Summer Sunshine in July. 2018. Available online: https: / / www.maltairport.com/malta-basks-363-hours-summer-sunshine-july/ (accessed on 7 August 2020).

26. Humphreys, M.; Nicol, F. Understanding the adaptive approach to thermal comfort. ASHRAE Trans. 1998, 104, 991-1004.

27. Brager, G.S.; de Dear, R.J. Thermal adaptation in the built environment: A literature review. Energy Build. 1998, 27, 83-96. [CrossRef]

28. Humphrey, S.E.; Nahrgang, J.D.; Morgeson, F.P. Integrating motivational, social, and contextual work design features: A meta-analytic summary and theoretical extension of the work design literature. J. Appl. Psychol. 2007, 92, 1332-1356. [CrossRef]

29. De Dear, R.J.; Brager, G.S. The adaptive model of thermal comfort and energy conservation in the built environment. Int. J. Biometeorol. 2001, 45, 100-108. [CrossRef]

30. De Dear, R.J.; Brager, G.S. Developing an adaptive model of thermal comfort and preference. ASHRAE Trans. 1998, $104,1-18$.

31. Nicol, J.F.; Humphreys, M.A. Adaptive thermal comfort and sustainable thermal standards for buildings. Energy Build. 2002, 34, 563-572. [CrossRef]

32. Walikewitz, N.; Jänicke, B.; Langner, M.; Meier, F.; Endlicher, W. The difference between the mean radiant temperature and the air temperature within indoor environments: A case study during summer conditions. Build. Environ. 2015, 84, 151-161. [CrossRef]

33. Parkinson, T.; de Dear, R.; Brager, G. Nudging the adaptive thermal comfort model. Energy Build. 2020, 206, 109559. [CrossRef]

34. $\mathrm{HOBO}{ }^{\circledR}$ MX1101 Data Logger; Onset: Cape Cod, MA, USA, 2015.

35. $\mathrm{HOBO}^{\circledR} \mathrm{MX} \mathrm{CO} 2$ Logger (MX1102) Manual; Onset: Cape Cod, MA, USA, 2017; pp. 1-12.

36. Aron, A.; Coups, E.J.; Aron, E.N. Statistics for Psychology, 6th ed.; Pearson Education Limited: Upper Saddle River, NJ, USA, 2013.

37. Yousaf, M. Research Design-Types of Research Design. 2018. Available online: https://scholarshipfellow.com/research-designtypes-research-design/ (accessed on 7 August 2020).

38. Patten, M.L.; Newhart, M.; Patten, M.L.; Newhart, M. Simple random and systematic sampling. In Understanding Research Methods; Routledge: New York, NY, USA, 2017. [CrossRef]

39. Formplus. The 4,5, and 7 Point Likert Scale. 2005. Available online: https://www.formpl.us/blog/point-likert-scale (accessed on 7 August 2020). 
40. Hawkes, D.; McDonald, J.; Steemers, K. The Selective Environment: An Approach To Environmentally Responsive Architecture; Taylor \& Francis: Abingdon, UK, 2001.

41. Shahzad, S.; Brennan, J.; Theodossopoulos, D.; Calautit, J.K.; Hughes, B.R. Does a neutral thermal sensation determine thermal comfort? Build. Serv. Eng. Res. Technol. 2018, 39, 183-195. [CrossRef]

42. David, P.L.D.; Rioli, T.O.; Prado, B.B.; Faria, J.R.G.; Fontes, M.S.G.C. Thermal perception of users of different age groups in urban parks in warm weather conditions. In Proceedings of the 30th International PLEA Conference, Ahmedabad, India, 16-18 December 2014.

43. IBM SPSS Software; IBM: Armonk, NY, USA, 2019. Available online: https://www.ibm.com/analytics/spss-statistics-software. (accessed on 12 June 2019).

44. McLeod, S.A. What a p-Value Tells You About Statistical Significance. 2019. Simply Psychology. Available online: https: / / www.simplypsychology.org/p-value.html (accessed on 15 March 2021).

45. McHugh, M.L. The Chi-square test of independence. Biochem. Med. 2013, 23, 143-149. [CrossRef] [PubMed]

46. Weather Forecast Office. A Discussion of Water Vapor, Humidity, and Dewpoint, and Relationship to Precipitation, Discuss; National Weather Service, National Oceanic and Atmospheric Administration: Louisville, KY, USA, 2020. Available online: https: //www.weather.gov/lmk/humidity (accessed on 7 August 2020).

47. Lu, S.; Li, Z.; Zhao, Q. Thermal process of windows in hot summer and cold winter climate. Procedia Eng. 2015, 121, 1788-1794. [CrossRef]

48. Vella, R.C.; Martinez, F.J.R.; Yousif, C.; Gatt, D. A study of thermal comfort in naturally ventilated churches in a Mediterranean climate. Energy Build. 2020, 213, 109843. [CrossRef]

49. Lymath, A. What Is a U-Value? Heat Loss, Thermal Mass and Online Calculators Explained; NBS: Newcastle, UK, 2015.

50. Zhai, Y.; Zhang, Y.; Meng, Q.; Chen, H.; Wang, J. Gender differences in thermal comfort in a hot-humid climate. In Proceedings of the 13th International Conference on Indoor Air Quality and Climate, Hong Kong, China, 7-12 July 2014. Available online: https: / / escholarship.org/uc/item/2hz2s45r (accessed on 7 August 2020).

51. Kingma, B.; Van Marken Lichtenbelt, W. Energy consumption in buildings and female thermal demand. Nat. Clim. Chang. 2015, 5, 1054-1056. [CrossRef]

52. Blatteis, C.M. Age-dependent changes in temperature regulation-A mini review. Gerontology 2012, 58, 289-295. [CrossRef]

53. Gallo, C. Chapter 5-The utilization of microclimate elements. Renew. Sustain. Energy Rev. 1998, 2, 89-114. [CrossRef]

54. Kuru, M.; Calis, G. Investigating the link between $\mathrm{CO}_{2}$ concentration, thermal comfort and occupant perception in educational buildings. In Proceedings of the 2018 Symposium on Simulation for Architecture and Urban Design (SimAUD 2018), Delft, The Netherlands, 4-7 June 2018. [CrossRef]

55. Development of WHO. Guidelines for Indoor Air Quality—Report on a Working Group Meeting Bonn, Germany, 23-24 October 2006; World Health Organization Regional Office for Europe: Copenhagen, Denmark, 2006. Available online: https://www.euro.who. int/_data/assets/pdf_file/0007/78613/AIQIAQ_mtgrep_Bonn_Oct06.pdf (accessed on 23 August 2020).

56. European Standard EN 16798-1: Energy Performance of Buildings-Ventilation for Buildings; Part 1: Indoor Environmental Input Parameters For Design and Assessment of Energy Performance of Buildings Addressing Indoor Air Quality, Thermal Environment, Ligh; British Standards Institution: London, UK, 2019.

57. Engeneering Toolbox. Carbon Dioxide Concentraion Levels-Comfort Levels. 2008. Available online: https://www. engineeringtoolbox.com/co2-comfort-level-d_1024.html (accessed on 4 March 2021).

58. Zhao, X.; Yu, W.; Tan, D. Thermal comfort study based on questionnaire survey among occupants in different climate zones in china. Int. J. Environ. Sci. Dev. 2017, 8, 430-434. [CrossRef]

59. Designing Buildings Wiki. Heat Gain. 2020. Available online: https://www.designingbuildings.co.uk/wiki/Heat_gain (accessed on 7 August 2020). 